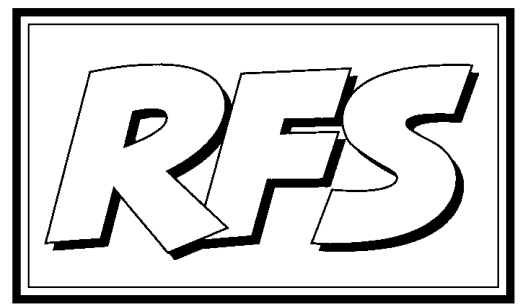

Revista de Fomento Social, 53 (1998), 223-270

\title{
Pobreza y desarrollo en el Este de Asia:
}

\section{¿lecciones para América Latina?}

Para bien y para mal, los países del Este de Asia «están de moda». A pesar de la crisis financiera de finales del 97, o quizás más precisamente por ella, sigue resultando de interés profundizar en algunos elementos fundamentales de la economía de esos países. Este trabajo intenta analizar hasta qué punto la lucha contra la pobreza ha formado parte del modelo «asiático» de desarrollo, en contraposición a lo ocurrido en América Latina. El autor procura evitar los dos extremos, la exaltación y la demonización, entre los que han oscilado de forma quizás excesivamente pendular muchos juicios de economistas e instituciones sobre estos países llamados emergentes.

$(*)$

(*) Director de la sede de Intermón de Sevilla. El presente texto constituye una versión 


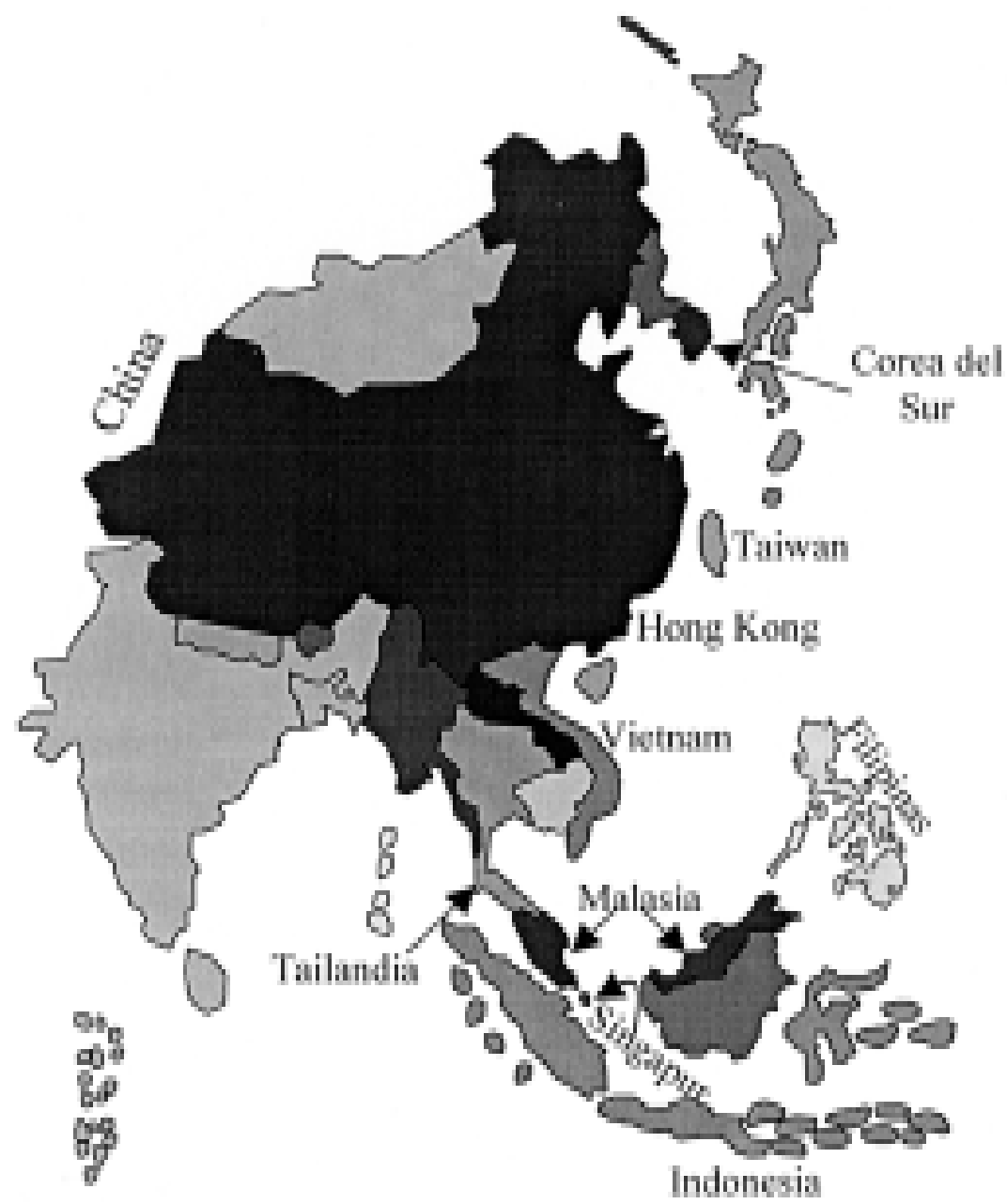

corregida de la ponencia presentada en el marco del Seminario de Doctorado sobre «Estrategias de desarrollo e integración económica en América Latina en los años 90», celebrado durante el curso 97/98 en la Facultad de CC. Económicas y Empresariales ETEA, adscrita a la Universidad de Córdoba, y dirigido por los profesores Pedro Caldentey, $\mathrm{M}^{\mathrm{a}}$ Luz Ortega y José J. Romero. El autor agradece a dichos profesores y al Consejo de Redacción de la Revista de Fomento Social sus observaciones a la primera versión del trabajo, aunque asume la responsabilidad del texto final resultante. 


\section{Introducción}

La pobreza de millones de personas en el fin de este milenio es un insulto a la humanidad. El pensamiento único no encuentra razones de escándalo en esta realidad, transmitiendola idea de que la pobreza es inevitable (1). En la actualidad hay más pobres en América Latina que hace 20 años. En África hay más pobres y más porcentaje de población en la pobreza. Y sin embargo en el Este de Asia se ha producido la mayor reducción de la pobreza que ha existido en la Historia: entre 1970 y 1990 se ha pasado de uno de cada tres a uno de cada diez habitantes en la pobreza; 645 millones de personas más viven hoy por encima del umbral de la pobreza que hace 25 años.

Sin embargo, el gran crecimiento de las economías asiáticas, vigoroso y sostenido durante casi tres décadas, ha ocultado la «revolución silenciosa» de la disminución de la pobreza.

El impresionante proceso de crecimiento de las economías de los países del Este de Asia y los aún más impresionantes logros de reducción de la pobreza en esta región han planteado desde hace años la urgencia de identificar los rasgos de un modelo aparentemente exitoso, para aplicarlo a otras zonas del planeta, específicamente América Latina

Existen en las reflexiones sobre el desarrollo dos posibles riesgos. Por un lado, concebir el desarrollo como un milagro inexplicable, que implicaría, de una manera fatalista, dejar a las fuerzas espontáneas del mercado la tarea de activar el conjunto de transformaciones deseadas para una sociedad concreta. Por otro lado, está el riesgo de creer que existen fórmulas, modelos, que permiten definir recorridos prefijables, aplicables en cualquier momento y a cualquier sociedad para que ésta se desarrolle.

(1) Los provinciales de los jesuitas de América Latina señalan que «la concepción neoliberal del ser humano considera normal que nazcan y mueran en la miseria millones de hombres y mujeres del continente incapaces de generar ingresos para comprar una calidad de vida más humana. Por eso los gobernantes y las sociedades no experimentan el escándalo frente al hambre y la incertidumbre de multitudes desesperanzadas y perplejas ante los excesos de los que usan, sin pensar en los demás, los recursos de la sociedad y de la naturaleza». Provinciales Latinoamericanos de la Compañía de Jesús, Neoliberalismo en América Latina. Aportes para una reflexión común. Documento de trabajo, 14 de noviembre de 1996, México. 
Ambos «vicios» lo son cuando se afirman de manera absoluta, de ahí el reto de conjugar el aprendizaje de las experiencias ajenas -pero evitando hacerlo como mera imitación- con que este aprendizaje se haga evitando la «metafísica del caso único» (2).

La mayoría de los análisis comparativos de los países del Este de Asia y América Latina pretenden caracterizar un modelo de desarrollo asiático para intentar aplicarlo a América Latina. Pensamos que pretender definir «un modelo único» puede llevar a sucumbir en el segundo riesgo del que hemos hablado. Las diferencias entre los países de los que hablamos son tantas, que no podemos establecer un modelo, sino identificar medidas concretas que han demostrado ser eficaces para lograr un crecimiento económico con ciertos niveles de equidad.

Pero además, buena parte de los análisis comparativos se centran en el crecimiento y la industrialización, considerando la equidad del crecimiento como un dato más ex post de los procesos. Este trabajo quiere centrarse en la forma en que se ha producido la reducción de la pobreza, y cómo ésta es a la vez causa y consecuencia directa de un proceso de crecimiento económico con equidad.

La idea central del trabajo es que la pobreza es evitable, que existen medidas que propician el crecimiento con equidad, que permiten la drástica reducción de la pobreza y el crecimiento sostenido de las economías. Es más, que los avances en la erradicación de la pobreza generan mejores condiciones para un crecimiento de la economía vigoroso y sostenido.

La crisis financiera que están sufriendo las economías del Este de Asia añaden aún interés al estudio. Desde nuestro punto de vista, esta crisis no es la demostración de la no-validez de un modelo, sino la consecuencia de medidas erróneas, y que además puede suponer la excusa perfecta para que el Fondo Monetario Internacional (FMI) imponga condiciones de ajuste que hagan peligrar los logros económicos y sociales.

Por esta razón en este trabajo se pretende identificar algunas políticas que han redundado en resultados positivos para el desarrollo de los países del Este de Asia y que podrían aplicarse en América Latina, identificando igualmente los lados oscuros de la experiencia asiática, que son muchos sobre todo en lo referente a las libertades sociales y políticas, para evitarlos.

(2) Término utilizado por Ugo Pipitone para referirse al primer riesgo. Él los caracteriza como la Metafísica y el Positivismo del desarrollo. PiPrtone, U. (1996), Asia y América Latina. Entre el desarrollo y la frustración. 


\section{Comparaciones académicas del Este de Asia con América Latina y nuevas visiones del «milagro asiático»}

Varios países del Este de Asia han experimentado entre 1970 y la actualidad un período de crecimiento económico sostenido espectacular. Este hecho ha venido a coincidir con diferentes crisis económicas profundas vividas en todo el mundo, y con especial intensidad durante los años 80 en América Latina. Por esta razón existen no pocos estudios que pretenden comparar los procesos de desarrollo de países concretos y que sacan conclusiones diversas sobre las razones de la diferencia. En algunos de estos estudios se hace referencia a la distribución de la riqueza, tan diferente en una y otra zona.

Los países del Este de Asia a los que nos referimos son Corea del Sur, Taiwan, Singapur, Hong Kong, Indonesia, Tailandia, China, Malasia y Vietnam. El siguiente cuadro ayudará a situar estos países en sus datos básicos geográficos, demográficos y económicos:

CUADRO $n^{\circ} 1$

Variables de los países del Este de Asia objeto de estudio

\begin{tabular}{|l|r|r|r|r|r|r|}
\hline & $\begin{array}{c}\text { Extensión } \\
\left(\mathrm{m}^{2}\right)\end{array}$ & \multicolumn{1}{|c|}{$\begin{array}{c}\text { Podbaón } \\
\text { (millones-1995) }\end{array}$} & \multicolumn{2}{|c|}{ PIB(milmillones\$) } & \multicolumn{2}{|c|}{$\begin{array}{c}\text { Expotzaiones } \\
\text { (milmillones) }\end{array}$} \\
\hline & & & 1975 & 1995 & 1975 & 1995 \\
\hline Coreadel Sur & 99.484 & 44.850 .000 & 22,43 & 431,80 & 4,46 & 125,10 \\
\hline Taiwan & 35.980 & 21.309 .000 & & 266,4 & & 111,59 \\
\hline Singapur & 618 & 2.990 .000 & & 75,68 & & 118,27 \\
\hline HongKong & 1.045 & 6.200 .000 & 10,90 & 151,30 & 5,97 & 173,10 \\
\hline Indonesia & 1.913 .000 & 193.750 .000 & 30,30 & 195,66 & 7,43 & 44,18 \\
\hline Tailandia & 514.000 & 60.200 .000 & 16,10 & 158,90 & 2,44 & 55,5 \\
\hline China & 9.596 .961 & 1.221 .300 .000 & 160,30 & 630,20 & 18,10 & 148,80 \\
\hline Malasia & 329.750 & 20.140 .000 & & 80,34 & & 74,05 \\
\hline Vietnam & 333.000 & 74.500 .000 & 7,94 & 13,77 & 0,82 & 2,99 \\
\hline
\end{tabular}

Fuente: El estado del mundo, 1997 


\subsection{Diversas interpretaciones}

De una manera resumida, existen diferentes perspectivas desde las que se ha analizado el desarrollo en los países del Este de Asia y de América Latina. Aunque válidas para determinados aspectos de la realidad, para determinados países o para períodos concretos, sin embargo fallan cuando se pretende ampliar su ámbito de aplicación. Siguiendo a Gary Gereffi (3) y de manera muy resumida enumeramos a continuación estos intentos y las críticas que se les hacen.

Para empezar, se pretende explicar las diferencias del desarrollo por las diferentes tradiciones culturales: la confuciana en Asia que valora el trabajo, la obediencia, la disciplina, la austeridad, y que permitió concertar el progreso social por encima de los intereses individuales, y de otro lado, la tradición católica, que con su mundo de valores ha dificultado el desarrollo de América Latina. Esta interpretación se salta la importancia que en amplias zonas del Este de Asia tiene el budismo, el Islam y el propio cristianismo, y que ambas tradiciones han existido durante siglos, y estamos analizando un proceso de desarrollo ocurrido en las últimas décadas. En definitiva, las diferencias sociales, culturales y religiosas entre países son tantas y la diversidad en su interior a veces tan grande, que pretender establecer un carácter asiático y convertirlo en la razón última del proceso de crecimiento de esta región resultaría simplificar demasiado la realidad que queremos analizar.

La literatura en torno a la división internacional del trabajo pretende explicar las oleadas de exportaciones de productos elaborados en Asia a partir de la explotación que las transnacionales harían de las grandes reservas de mano de obra existentes. Pero al analizar el creciente contenido tecnológico y relación con la industria local se puede rechazar que la industria creada sea meros «enclaves de exportación».

La perspectiva de la globalización de la producción señalaría el papel de creciente control por parte de las corporaciones transnacionales (CTN) de los procesos económicos y su influencia en los gobiernos. No obstante, la participa-

(3) Su análisis aparece en el artículo «Los nuevos desafíos de la industrialización: observaciones sobre el sudeste asiático y Latinoamérica». Pensamiento Iberoamericano, España, $\mathrm{n}^{\circ}$ 16, pp.205-234, se basa en comparar del Este de Asia a Corea del Sur, Taiwan, Hong Kong y Singapur con Brasil, Méjico y Argentina en América Latina. 
ción en el sector exportador de la industria local -aun en el modo de subcontratación- es mayor que el de las CTN.

Desde los 70 se acuñó el término Países de Reciente Industrialización (NIC en su sigla en inglés) para los países que aumentaban su participación mundial en la producción y exportación de productos elaborados y ante los que se piden barreras de protección. Pero, por un lado, su proceso de industrialización no es tan reciente y, por otro, los estudios se han basado en la industrialización de productos elaborados, marginando de su análisis a los países ricos en recursos naturales.

Desde la perspectiva neoclásica, el modelo de industrialización hacia fuera asiático triunfó netamente sobre el modelo aplicado en América Latina de industrialización hacia dentro. En realidad no hay una diferencia tan nítida de procesos, y en ambas regiones se han combinado ambos modelos, aunque de diferentes maneras.

Para la teoría de los sistemas mundiales los NIC son países semiperiféricos: realmente no forma parte de la periferia, de la que de alguna manera «han escapado», pero no pueden acceder al centro. Este análisis que no señala diferencias entre regiones ni países es considerado como demasiado simplista.

En los teóricos de la dependencia se puede observar una evolución que va desde los que consideran que de la dependencia de los países del Este de Asia o de América Latina sólo podría venir subdesarrollo, a los que consideran que esa situación no coarta la posibilidad de desarrollo capitalista. En cualquier caso, la dependencia en Asia ha venido de la ayuda exterior y del comercio internacional, en tanto que en América Latina ha venido de los vínculos con la banca y empresas transnacionales. Las capacidades de convertir estas dependencias en ventajas para los propios países es una de las diferencias entre las grandes áreas mundiales.

Para otros estudios la clave que define los procesos de desarrollo ha estado en la existencia de estados desarrollistas, autoritarios, con participación activa en la economía. Pero se pasan por alto las importantes diferencias de objetivos, base social y estrategias seguidas por los diferentes estados de cada país del Este de Asia o de América Latina.

Resultaría inapropiado simplificar las diferencias de la industrialización del Este de Asia y América Latina señalando que los primeros optaron por una 
industrialización hacia fuera y los segundos por una industrialización hacia dentro.

Existirían cinco etapas importantes del desarrollo industrial: tres orientadas hacia afuera y dos hacia adentro.

1. Fase de exportación de productos primarios. Exportación de materias primas y productos semiprocesados (productos agrícolas, minerales, petróleo, etc.)

2. Industrialización orientada a la exportación (IOE) primaria. Exportaciones de productos intensivos en uso de mano de obra.

3. Industrialización orientada a la exportación(IOE) secundaria. Exportaciones de productos con más valor agregado que demandan un mayor desarrollo de la industria local.

4. Industrialización sustitutiva de importaciones (ISI) primaria. Cambio de importaciones por producción de bienes de consumo básicos: textiles, calzados, procesamiento de alimentos, etc.

5. Industrialización sustitutiva de importaciones (ISI) secundaria. Producción nacional de bienes intensivos en tecnología y capital: productos intermedios (acero, productos petroquímicos), bienes de capital (maquinaria pesada) y productos duraderos (coches).

Todos los países han vivido etapas de ISI primaria con protección de su industria, que pretendía satisfacer la demanda interna. En el cuadro $n^{\circ} 1$ aparecen señaladas las diferentes etapas para los países del estudio.

La utilización combinada de estrategias de sustitución de importaciones y de orientación a las exportaciones demuestra que ambas estrategias más que excluyentes han sido complementarias. Las diferencias básicamente han venido por la diferente respuesta que desde una y otra región se han dado a los problemas que provocan las estrategias de sustitución de importaciones: déficit de balanza de pagos, inflación, dependencia de productos intermedios, etc.

La conclusión final que se señala es que la industrialización resulta cada vez menos significativa como indicador de desarrollo, y tan es así, que incluso con niveles similares de industrialización, los logros en desarrollo son notablemente mayores en los países del Este de Asia que en Méjico o Brasil. 


\section{GRÁFICO n ${ }^{\circ} 1$ \\ Vías de industrialización en América Latina y el sudeste asiático: puntos en común, divergencias y convergencias}

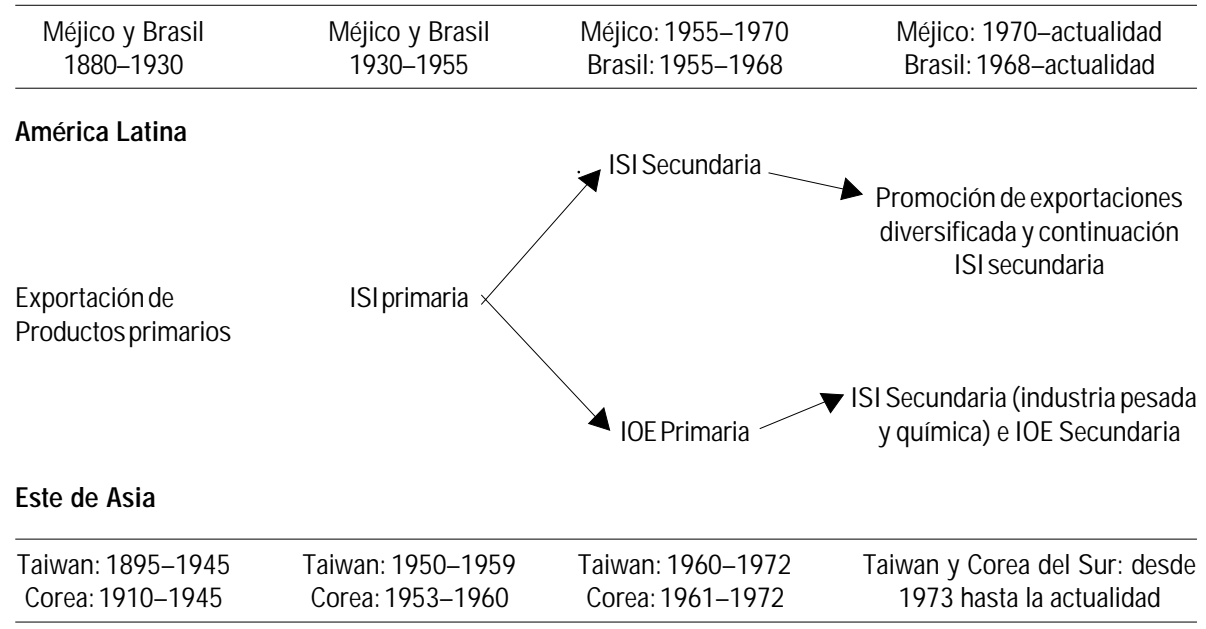

Para Pablo Bustelo (4), la explicación más extendida, según la cual, la diferencia del proceso de industrialización del Este de Asia y de América Latina está en que en la primera región se dio una industrialización orientada a la exportación, una liberalización amplia de la economía y unos estados no intervencionistas, mientras que en América Latina fueron unos estados muy pesados los que plantearon estrategias de industrialización hacia dentro y mantuvieron un fuerte intervencionismoen economía, resulta una interpretación simplista y alejada de la realidad.

En primer lugar la contraposición entre estrategias de Industrialización Orientadas a la Exportación e Industrialización Sustitutoria de Importaciones resulta una simplificación que no se corresponde con la realidad. Los países del Este de Asia también han tenido etapas de ISI, aunque más cortas, y han tenido

(4) Bustelo, P., «Pautas comparadas de Industrialización: los NPI de Asia y de América Latina». Boletín Económico del ICE. Hace todo su estudio referido sólo a los países ya señalados en cada región: Taiwan, Corea del Sur, Hong Kong, Singapur, Brasil y Méjico. 
una percepción distinta del mercado de exportación, al que han visto como el sector que provocaría el arrastre del conjunto de la economía, por los excedentes financieros y por la demanda de productos intermedios que suministrarían los sectores no exportadores de la industria nacional. Frente a ello, en América Latina, el sector exportador no ha sido concebido como la base del crecimiento, sino como un medio de obtener divisas.

En segundo lugar la estrategia liberal que supuestamente habrían seguido los países del Este de Asia no se corresponde con sus historias económicas. Como luego se verá, esta interpretación distorsionada de la realidad es interesada y viene a constituir una suerte de mito inexistente. La realidad desmiente la tesis de una apertura indiscriminada al exterior y un liberalismo a ultranza en el interior. Las tasas de protección de estos países no han sido ni mucho menos bajas: Corea del Sur pasó de una tasa media de protección efectiva del 13\% en 1968 al 32\% en 1978, en tanto que Méjico tenía un índice de 11\% en 1979.

Por último, sobre el papel de los estados, su intervención ha sido mucho más intensa en los países del Este de Asia que en Méjico o Brasil. Sirva el siguiente cuadro de ejemplo:

\section{CUADRO $\mathrm{n}^{\circ} 2$}

\section{Relación Gasto Público/PIB en el Este de Asia y América Latina} (en porcentaje)

\begin{tabular}{|l|l|l|l|l|}
\hline & $\mathbf{1 9 6 5}$ & $\mathbf{1 9 7 0}$ & $\mathbf{1 9 7 5}$ & $\mathbf{1 9 8 0}$ \\
\hline Corea del Sur & $16,7(\mathrm{a})$ & 17,2 & 17,2 & 20,3 \\
\hline Singapur & 20,9 & 20,1 & 23,1 & 24,9 \\
\hline Taiwan & 21,1 & 23,5 & 23,0 & 26,7 \\
\hline Hong Kong & 16,7 & $11,3(\mathrm{~b})$ & $11,1(\mathrm{c})$ & $11,6(\mathrm{~d})$ \\
\hline Brasil & 10,2 & 10,2 & 9,4 & 9,2 \\
\hline Méjico & $11,1(\mathrm{a})$ & 10,9 & 17,0 & 18,9 \\
\hline
\end{tabular}

(a) 1966, (b) 1968, (c) 1976, (d) 1979

Fuente: Oxfam Internacional

La diferencia ha venido sobre todo por la diferente naturaleza de los estados de una y otra región. Aunque hay casos flagrantes de lo contrario, como 
Indonesia, al menos algunos estados del Este de Asia parecen haber sido en general más fuertes y autónomos de las oligarquías locales que los de América Latina, lo que les ha permitido acometer unas profundas reformas agrarias que dieron paso a un crecimiento agrícola muy rápido, a un proceso de industrialización rural y a una distribución más equitativa de la renta. Por otrolado han podido dar un impulso grande a la transición hacia la industria exportadora.

\subsection{La revolución silenciosa}

Pero hay en el proceso de desarrollo de los países del Este de Asia un acontecimiento capital: se ha producido en tres décadas la mayor reducción de la pobreza que se ha dado jamás en la historia. En tres décadas se ha pasado en estos países de que vivieran en la pobreza una de cada tres personas a que lo hagan hoy una de cada diez y a que 645 millones de personas más vivan hoy por encima del umbral de la pobreza que hace tres décadas.

Teniendo en cuenta estos datos formularíamos la pregunta ¿existen estrategias que hayan permitido a los países del Este de Asia reducir la pobreza y crecer?, ¿son aplicables a otras zonas del mundo estas estrategias?

La revolución silenciosa que ha supuesto la reducción de pobreza más rápida y amplia en número de personas que ha vivido jamás la humanidad tiene también importantes aristas oscuras: gobiernos abiertamente hostiles a los principios democráticos, crecimiento acompañado muchas veces de explotación laboral (especialmente de la mano de obra femenina, con largas jornadas laborales, peligrosidad en el trabajo, ausencia de seguridad social, etc.), destrucción acelerada del medio ambiente. Igualmente existen aún graves problemas de pobreza en estos países, que afectan sobre todo a poblaciones campesinas e indígenas, y existen cinturones de miseria en las ciudades. Y por si esto fuera poco, el proceso de crecimiento económico da preocupantes señales de ralentización.

Tomar como ejemplo las exitosas estrategias que han permitido reducir la pobreza en el Este de Asia no debe hacernos olvidar el lado oscuro de estas sociedades, cuyas manifestaciones más extremas se están observando tras la crisis de los mercados financieros regionales. La pobreza no es sólo bajos ingresos y falta de acceso a los servicios básicos, también es la falta de acceso a las libertades políticas, la falta de respeto a los derechos de la mujer, la vida en 
un medio ambiente deteriorado.

Si el reto para otras regiones, especialmente América Latina, es alcanzar los logros en erradicación de la pobreza que ha vivido el Este de Asia, para estos países, el gran reto ha de ser permitir que sus ciudadanos tengan acceso a la participación social y política de sus sociedades.

\subsection{Dos generalizaciones erróneas}

Pese a la diversidad enorme entre los países asiáticos se han producido, como ya hemos señalado, innumerables esfuerzos por explicar simplificadamente la clave del éxito asiático.

Para unos la clave estaba en el carácter autoritario de los gobiernos que, para los defensores de este planteamiento, refleja los valores asiáticos: la sociedad se encuentra por encima de los individuos. Para ellos los derechos humanos son un concepto occidental que les resulta ajeno.

Para otros el factor crítico del éxito asiático ha sido la aplicación de los principios del libre mercado: liberalización comercial, desregulación financiera y los principios del mercado son la causa del crecimiento y de la reducción de la pobreza. El FMI y el Banco Mundial pusieron durante años la experiencia asiática -o más bien su interpretación de la misma-como el modelo a seguir.

$\mathrm{Si}$, como proponen los primeros, los gobiernos autoritarios fueran garantía de desarrollo económico, algunos países de América Latina y África serían superpotencias. El autoritarismo sólo acoge corrupción y servidumbres a los grandes intereses. Por otra parte las continuas protestas a favor de la democracia desde Tiananmen a Corea del Sur, y las actuales de Indonesia revelan que los asiáticos aspiran a la democracia y se rebelan contra los gobiernos autoritarios que padecen. Insistimos en que este es uno de los más importantes pasivos de esta región, que los éxitos cosechados en otros campos no deben ocultar.

Por otro lado, las políticas de regulación del comercio e inversiones públicas en los países del Este de Asia desmienten las recetas del BM y del FMI, que están llevando a asumir reformas liberalizadoras muy profundas en países de América Latina, con evidentes falta de éxito tanto en la lucha contra la pobreza como en el crecimiento económico.

El verdadero origen del «milagro asiático» ha estado en la aplicación de políticas que han dado un fuerte impulso al desarrollo humano con inversiones 
públicas en salud primaria y en educación, en la redistribución de los activos productivos, en las inversiones en los pobres y en políticas de crecimiento basadas en el uso intensivo de la mano de obra.

De esta manera en el Este de Asia el crecimiento económico y la reducción de la pobreza han establecido vínculos que se refuerzan mutuamente, habilitando a los pobres para que encuentren sus propias vías de salir de la pobreza participando activamente en la creación de riqueza, más que esperar que les gotee poco a poco la riqueza generada por otros.

Las estrategias a las que hacíamos referencia, por otra parte aplicadas en cada lugar de manera diferenciada, son tratadas a continuación.

\section{Lecciones de Asia: las políticas de expansión de oportunidades; condiciones para que se den crecimiento y equidad}

Como se dijo antes, el Banco Mundial proponía un «modelo asiático» basado en el libre mercado como patrón de desarrollo. El modelo propuesto es básicamente un invento del Banco Mundial para sostener un mito.

Mito por dos razones. En primer lugar porque no existe un único modelo. Las diferencias entre los distintos países han sido muchas, y de ellas se han seguido también resultados diferentes en la combinación de crecimiento y equidad. En segundo lugar, porque las políticas de estos países no son precisamente la receta que el Banco Mundial está dando a los países en desarrollo de América Latina como modelo de crecimiento.

No se puede ofrecer un modelo únicoe invariable, porque no lo ha habido para los países del Este de Asia: Taiwan no copió a Corea del Sur, Indonesia no copió a Taiwan y China y Vietnam no han copiado a Malasia. Tampoco se pueden ofrecer recetas que no tengan en cuenta las riquezas, tradiciones históricas, sistemas administrativos y diferencias entre países. Pero sí se pueden sacar algunas lecciones de lo sucedido en Asia.

\subsection{Primera lección: la pobreza no es inevitable}

La lección más importante es también la más sencilla: la rápida erradicación de la pobreza es posible.

En los años 60 los índices de pobreza y de dependencia económica de los 
países del Este de Asia eran comparables a los del África sub-sahariana. Probablemente para los analistas de entonces haber pronosticado la situación actual de esta zona hubiese sido pasar por utópicos, además de haber hecho el ridículo(5).

La experiencia de los países del Este de Asia pone de manifiesto que los avances contra la pobreza son posibles en la práctica. La primera lección para América Latina y para la Comunidad Internacional es que la pobreza no debe ser tolerada. No puede ser tolerada.

\subsection{Segunda lección: el crecimiento con equidad es la llave del éxito}

El crecimiento es percibido por los defensores de posturas más neoliberales como la única fuente de lucha contra la pobreza. Para posturas antagónicas, el crecimiento económico sólo es fuente de ensanchamiento de la brecha entre ricos y pobres.

Si bien es cierto que el crecimiento puede producirse beneficiando sobre todo a los más enriquecidos, prescindiendo de las mayorías, e incluso puede empeorar la situación de algunos grupos (por ejemplo, los pueblos indígenas de la Amazonía), lo cierto es que éstas no son situaciones inevitables.

El crecimiento por sí solo no es suficiente, son necesarias políticas de inclusión que permitan a los pobres participar del proceso de crecimiento económico. Es más, la lección de la experiencia asiática es que también son necesarias políticas que tiendan a mejorar la cobertura de otras necesidades básicas, tales como salud, alfabetización, esperanza de vida, etc. Es decir, a igualar las condiciones

(5) Xabier Gorostiaga, hace para Centroamérica un análisis en el que partiendo de la evidente existencia de una sociedad de dos ciudadanías (una minoría taiwanizada que alcanza un importante nivel de modernización e inserción internacional, y una mayoría africanizada que sufre una intensa pobreza) augura un «escenario desolador y sin alternativa» en el que para el año 2015 habrá una mayor dependencia, se sufrirá una mayor exclusión y desintegración social y se consolidarán democracias cada vez más superficiales y formales, y en el que el papel de la cooperación internacional será de subsidio y bálsamo de una situación que reproduce el subdesarrollo. Por supuesto el augurio se hace señalando que aunque se camina firmemente hacia su cumplimiento, existen alternativas. Gorostiaga, X. (1996), Entre Somalia y Taiwan. ¿Hay otra alternativa?, Envío, no 167, enero-febrero, Nicaragua, pp. 33-43. 
de capacitación, formación con las que se accederá al mercado y redistribuir los activos de producción.

Y la razón de esta inversión en los pobres no es sólo una exigencia ética, es también una demanda de la eficacia de la economía. Existe una influencia mutua negativa entre pobreza y falta de crecimiento económico: la pobreza reduce la productividad, disminuye la capacidad de ahorro e inversión, resta capacidad de consumo, limita las oportunidades de mercado para nuevos productores y desincentiva la producción y la creación de empleo, frenando el crecimiento.

Los mecanismos para alcanzar el crecimiento con equidad en el Este de Asia han sido variados, pero lo importante es que se logró establecer círculos virtuosos de crecimiento y reducción de pobreza. En otros países como Brasil, Méjico o la India la falta de atención a la reducción de la pobreza mediante medidas directas ha sido la causa no sólo de que no se hayan obtenido logros significativos en este campo, sino también de que no hayan logrado mantener ciclos de crecimientos sostenidos. En los países del Este de Asia los pobres se han beneficiado del crecimiento no porque les haya llegado algo de él como si goteara desde donde hay riqueza a donde no la hay, sino porque ha sido el desarrollo de su potencial productivo el auténtico eje del crecimiento económico.

Las medidas directas han sido claves en el logro del crecimiento con equidad y la rápida reducción de la pobreza. Aunque hay mucha literatura que estudia el crecimiento económico asiático, poca de ella repara, como hemos señalado, en que éste se basó en unos cimientos sociales construidos antes de que comenzara el crecimiento. Mientras que para la mayoría de los países las políticas sociales y las económicas van por caminos distintos, siendo las primeras las que se encargan de establecer colchones de protección social y las segundas las que atienden al crecimiento de la economía, en los países del Este de Asia las políticas de inversión en capital humano forman parte de las políticas económicas orientadas al crecimiento. La clave no se ha puesto tanto en la provisión de servicios por el Estado como en mejorar las posibilidades de los pobres de acceder a estos servicios.

Por otra parte, el desarrollo rural a través de la redistribución de los recursos es otro de los aspectos comunes en el Este de Asia. Las políticas de reforma agraria han permitido el acceso a la tierra y al crédito y mejorado las infraestructuras de comercialización, han liberado para los pobres todo un inmenso capital productivo que les ha habilitado para salir de la pobreza, y lo que es más, para 
reforzar el proceso de crecimiento económico con un sistema de pequeños propietarios más eficaz que las grandes explotaciones (6).

Además de lo anterior, y en contraste con otras regiones en vías de desarrollo, el crecimiento económico en los países del Este de Asia se ha asociado a altas tasas de creación de empleo. Las políticas de todos estos países han tendido a orientarse al libre mercado, pero esta orientación se ha dado en un marco de largo plazo. De esta manera, y con diferencias entre los países, se han dado procesos de proteccionismo selectivo, de regulación de las inversiones extranjeras y una política industrial activa orientada a la creación de empleo y la mejora de la productividad, lo que ha permitido el constante crecimiento de los salarios reales. En América Latina el proteccionismo no ha buscado tanto la eficiencia productiva sino que se ha orientado al crecimiento basado en el uso intensivo de capital, no de mano de obra. Esto ha provocado que países fuertemente industrializados como Brasil y Méjico no hayan reducido significativamente la pobreza.

Políticas sociales correctas, desarrollo rural a través de la redistribución de los recursos y políticas económicas encaminadas al fortalecimiento de industrias intensivas en el uso de mano de obra. Integrar exitosamente estos tres elementos parece la clave para conseguir crecimiento con equidad.

Países como China y Vietnam que comenzaron la liberalización de su economía a finales de los 70 y a mediados de los 80 respectivamente, habían comenzado dos décadas antes a aplicar políticas sociales como las descritas. Como contraste, quepa señalar a la India, donde las reformas liberalizadores de 1991 se hicieron en medio de un extremo analfabetismo y una pésima salud pública. Las reformas en este país han obtenido muy limitados efectos de crecimiento económico. Por su parte Brasil o Méjico han liberalizado sus economías en medio de una muy inequitativa distribución de los recursos productivos (especialmente la tierra), con lo que los resultados de crecimiento y erradicación de la pobreza han sido igualmente decepcionantes. Incluso ejemplos comoel de Zimbabwe enseñan mucho: unas acertadas políticas sociales han

(6) Gorostiaga, X., art. cit., identifica en una economía con uno de sus pilares en una estructura finquera de pequeños y medianos productores agropecuarios la alternativa al sombrío panorama dibujado anteriormente. Los pequeños y medianos campesinos del sector finquero serían los nuevos sujetos socioeconómicos portadores de un desarrollo más equitativo e intensivo en el uso de la mano de obra. 
mejorado mucho las condiciones de vida básicas, pero la concentración de la riqueza y de los recursos han frenado el crecimiento del país. La enseñanza es que mantener un tipo de políticas sociales como las emprendidas en este país exige recursos, y éstos sólo existirán si hay crecimiento.

Las políticas sociales necesitan el crecimiento económico que las mantengan tanto como el crecimiento necesita buenas políticas sociales para ser sostenido.

\subsection{Lección tercera: responsabilidad política}

Las diferentes situaciones de crisis vividas en los países del Este de Asia fueron empujando a sus gobernantes a giros en sus políticas, que comenzaron a dirigirse a la lucha contra la pobreza. Diferentes revueltas o fundados temores de las elites gobernantes de que la pobreza extrema de grandes capas de su población fuera una gran amenaza para la estabilidad de sus países les llevaron a asumir con responsabilidad política-quizá sólo con instinto de supervivenciacambios en la distribución de los recursos, destinados a los pobres (7).

La responsabilidad de los países occidentales en las políticas de los países en vías de desarrollo es inmensa. Europa responde a las oleadas de inmigrantes cerrando fronteras, y a los problemas de salud y los causados por la inestabilidad política en Africa con ayuda humanitaria y de emergencia, en lugar de destinar los fondos de cooperación a las causas que subyacen en las emergencias. EE.UU. declara guerras a los pequeños agricultores de América Latina a los que la falta de oportunidades les lleva a producir para los narcotraficantes.

La experiencia asiática demuestra que la estrategia de atender a los síntomas de la pobreza en lugar de comprometerse con sus causas es una estrategia equivocada.

(7) Gorostiaga, X., art. cit., por el contrario, mantiene que en Centroamérica la situación actual, de mantenerse, no llevaría a amenazar la estabilidad política, sino que generaría un «caos de baja intensidad». En lugar de desembocar en revoluciones armadas, los conflictos sociales provocarán una creciente descomposición del tejido social, convirtiendo las zonas rurales en zonas somalizadas y generando una gran inseguridad en las ciudades. Los gastos de seguridad serían tan altos que igualarían los gastos militares de los tiempos de guerra. La pregunta es si las élites latinoamericanas, formadas por las redes familiares oligarcas y las clases medias incorporadas al servicio de las mismas, consideran la pobreza de la mayoría de las poblaciones de sus países como un grave riesgo de inestabilidad. 


\section{Crecimiento con reducción de la pobreza}

\subsection{Algunos datos}

Los datos del crecimiento económico y de la reducción de pobreza que han experimentado los países del Este de Asia hablan por sí solos.

Respecto a la reducción de la pobreza, los datos del Banco Mundial señalan una evolución espectacular que se señala en el cuadro n ${ }^{\circ}$ 3: entre 1970 y 1990 suben el escalón de la pobreza 220 millones de personas. Este dato unido a que en este período la población creció en esta región en 425 millones de personas ponen de manifiesto que hoy viven en los países del Este de Asia 665 millones de personas más por encima del umbral de la pobreza.

\section{GRÁFICO 2}

Este de Asia: pobreza absoluta, 1970-1990

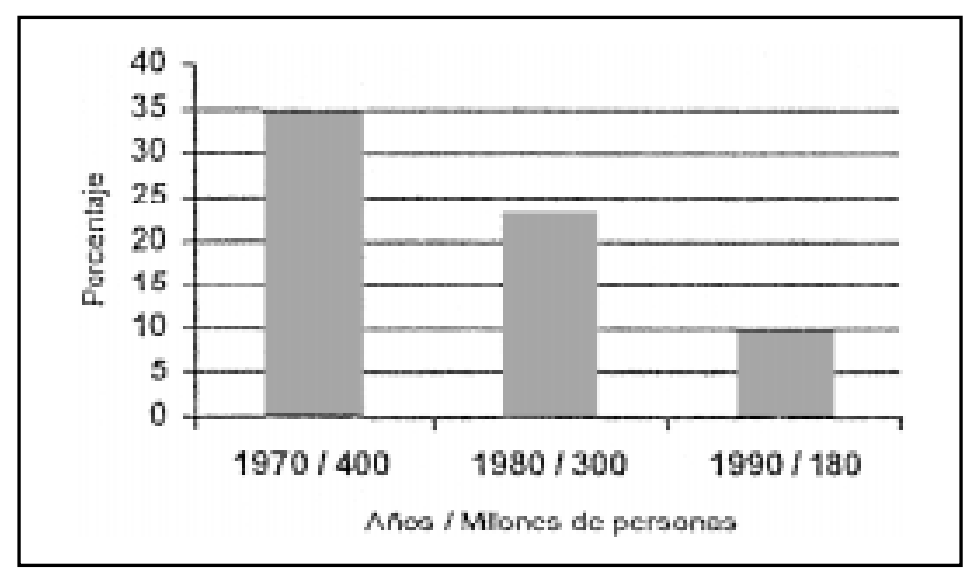

Fuente: Oxfam Internacional

Esta evolución es especialmente notoria en dos países: China, donde salen de la pobreza 175 millones de personas mientras la población crece en 300 millones, e Indonesia, donde 40 millones de personas han salido de la pobreza mientras la población ha crecido en 60 millones.

Aunque el espectacular crecimiento económico de estos países, especialmen- 
te de los de la primera etapa de industrialización, ha centrado la mayoría de los estudios, conviene repasar algunos datos que señalan la reducción de la pobreza en estas sociedades:

CUADRO $n^{\circ} 3$

\begin{tabular}{|l|c|c|c|c|}
\hline & \multicolumn{2}{|c|}{ PIBper cápita (US\$ 1987) } & \multicolumn{2}{c|}{ Esperanza de vida al nacer } \\
\hline & 1960 & 1994 & 1960 & 1994 \\
\hline Indonesia & 190 & 676 & 41,2 & 63,5 \\
\hline Tailandia & 300 & 1.703 & 52,3 & 69,5 \\
\hline India & 206 & 407 & 44,0 & 61,3 \\
\hline Bangladesh & 146 & 196 & 39,6 & 56,4 \\
\hline Nigeria & 329 & 349 & 39,5 & 51,0 \\
\hline
\end{tabular}

Fuente: PNUD

Las mejoras en los niveles de desarrollo humano no se deben sólo a mayores rentas e inversiones en los programas sociales que en otras regiones en desarrollo, se deben, fundamentalmente a un enfoque más adecuado del gasto social. Sirvan como ejemplos (8):

CUADRO $n^{\circ} 4$

\begin{tabular}{|l|c|c|}
\hline & PIBper cáp.(US\$) & Esp. de vida \\
\hline Vietnam & 1.208 & 66,0 \\
\hline Nigeria & 1.351 & 51,0 \\
\hline China & 2.604 & 68,9 \\
\hline Brasil & 5.362 & 66,4 \\
\hline
\end{tabular}

Fuente: PNUD

(8) Datos para el período 1990-1995, recogidos en el Informe sobre desarrollo humano 1997, del PNUD. 
CUADRO $n^{\circ} 5$

\begin{tabular}{|c|c|c|}
\hline & PIBpercáp.(US\$) & $\begin{array}{c}\text { Acceso serv. Salud } \\
\text { (\%población) }\end{array}$ \\
\hline Indonesia & 880 & $93 \%$ \\
\hline Perú & 2.110 & $44 \%$ \\
\hline
\end{tabular}

Fuente: PNUD

Vietnam es un claro ejemplo de cómo con unos bajos ingresos es posible conseguir importantes logros de desarrollo humano. Con un PNB per cápita de 1.200 dólares, muy inferior al de los países latinoamericanos (Perú: 2.110, Paraguay: 1.580, El Salvador: 1.360, Guatemala: 1.200) ha logrado desde 1980 mejorar la esperanza de vida en cuatro años, reducir la mortalidad infantil de 57 a 42 niños por cada 1.000 nacidos, alfabetizar al $90 \%$ de los adultos, y permitir el acceso a los servicios de salud del $93 \%$ de su población.

Acompañando a este «milagro» de reducción de la pobreza ha existido el ampliamente publicitado «milagro económico». Los datos de crecimiento económico de los países del Este de Asia de este período ponen de manifiesto la magnitud del despegue económico de la región. Con una media de crecimiento del $8 \%$ anual (lo que ha supuesto doblar el PIB cada seis a ocho años durante tres décadas) la brecha que se ha abierto entre esta región y otras en desarrollo es enorme, y especialmente significativa las diferencias con América Latina, región que antes de los 80 tenía índices de crecimiento similares a los asiáticos.

CUADRO $n^{\circ} 6$

Tasa de crecimiento anual medio del PIB en el Este de Asia y América Latina

\begin{tabular}{|l|c|c|c|}
\hline & $1965-1973$ & $1973-1980$ & $1980-1985$ \\
\hline Este de Asia & $7,9 \%$ & $6,5 \%$ & $7,8 \%$ \\
\hline América Latina y Caribe & $6,4 \%$ & $5,2 \%$ & $0,5 \%$ \\
\hline
\end{tabular}

Fuente: Banco Mundial: Informe sobre desarrollo mundial 1989 


\section{GRÁFICO 3 \\ Tasa de crecimiento anual medio del PIB en el Este de Asia y América Latina}

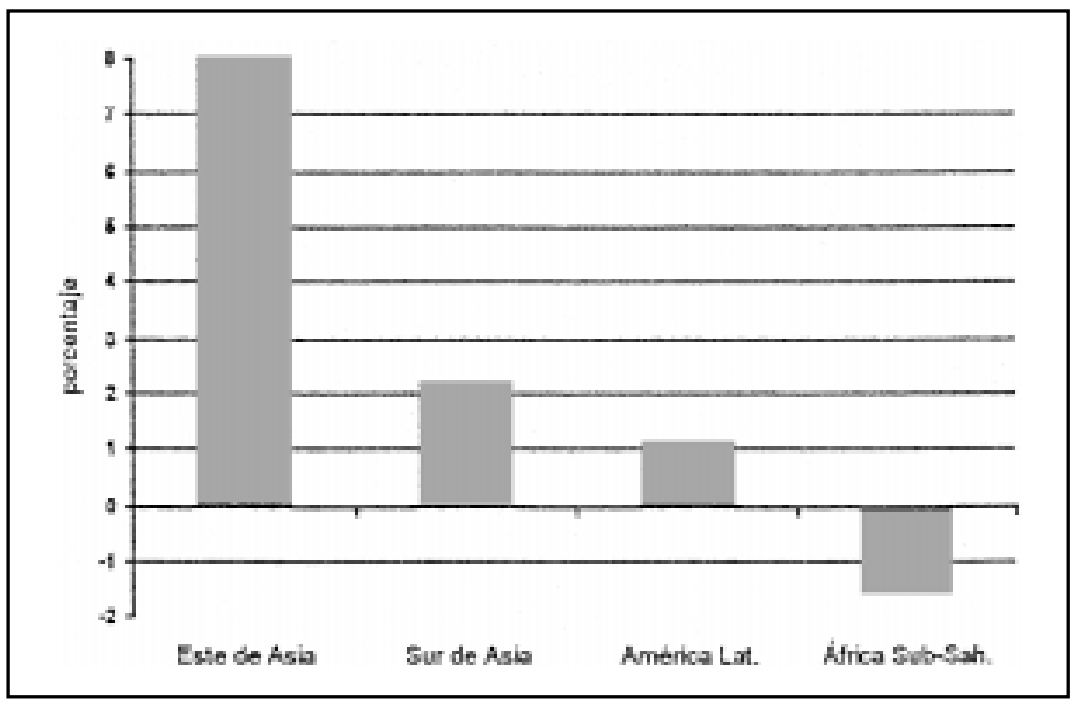

Fuente: Oxfam International

Las recientes turbulencias en las economías de esta región están llevando a generalizar la idea de que se puede extender la partida de defunción del modelo (9). Resulta curioso observar que tras años de euforia desmedida sobre las

(9) En una reciente entrevista concedida a El País (01-12-97, p. 62) Michel Camdessus, Director del FMI, afirmaba que la crisis en los países del Este de Asia ponía de manifiesto que el modelo asiático había pasado de moda. Camdessus condiciona el apoyo a los sistemas financieros que están sufriendo la crisis de los últimos meses a que, entre otras cosas, se reduzca el papel de los estados en la economía y se manejen presupuestos con superávit. También en El País (27-12-97, p. 56) el Instituto de Estudios Estratégicos de Londres planteaba la crisis con la pregunta « ¿El fin de la 'edad de oro’?». Se señala en este artículo que la crisis es planteada por los gobiernos de la zona, la mayoría poco democráticos, como una consecuencia de las acciones de los especuladores internacionales para desestabilizar las divisas de la región. Lo cierto es que estos mercados financieros padecen una gran dependencia ante la inversión extranjera para financiar sus 
perspectivas económicas de la región, ahora se haya pasado a un catastrofismo generalizado, que puede ser claramente injustificado (10).

Reiteramos, por último, que el crecimiento con equidad experimentado en los países del Este de Asia, y que ponen de manifiesto los índices de desarrollo humano y los índices de crecimiento económico (ver gráfico $\mathrm{n}^{\circ} 4$ ) deben servir para identificar las lecciones trasladables a otras regiones en desarrollo, como América Latina.

\section{GRÁFICO 4 \\ Crecimiento mundial, 1974-1994}

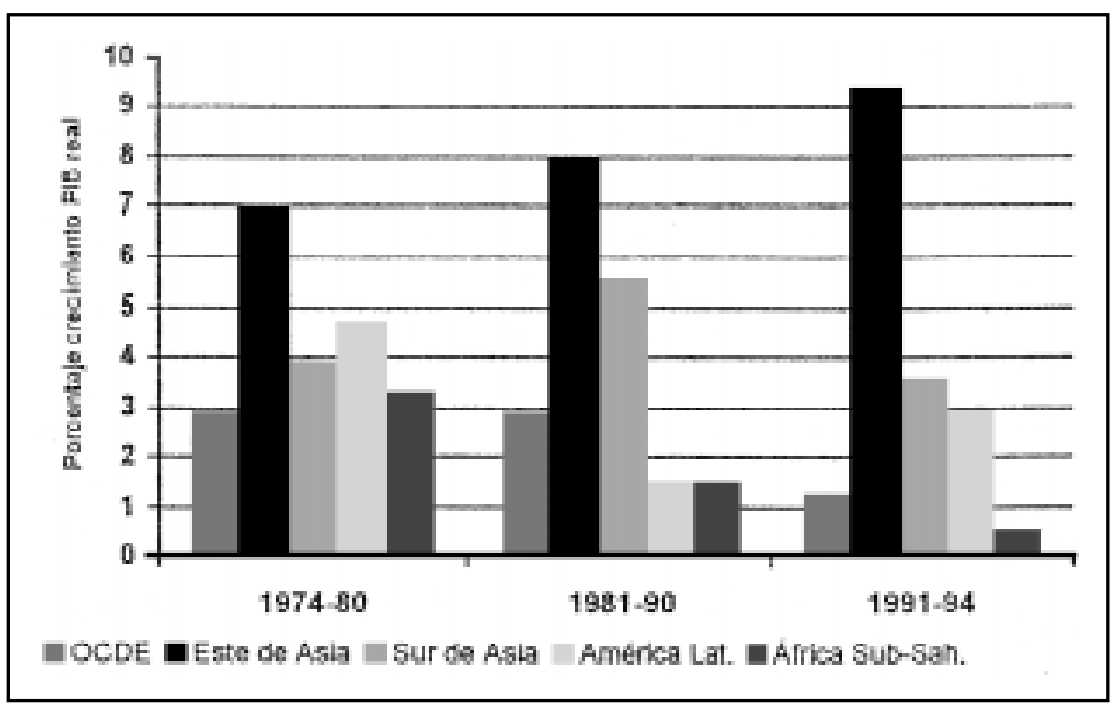

Fuente: Oxfam Internacional.

déficits, y esto provoca una enorme vulnerabilidad que puede empujar a sus dirigentes a buscar una mayor cohesión con Japón, China y Corea del Sur y a actuar con criterios más nacionalistas en política y en economía. Por último, y relacionando los acontecimientos del Este de Asia con América Latina, Julio Argüelles señala en El País (26-11-97, p. 58) la paradoja de que con un teórico de la dependencia en el poder (Fernando H. Cardoso), Brasil viva una situación en la que su economía -al igual que sucede con la de Tailandiasufre los elevados costos de la dependencia de los capitales internacionales.

(10) Pablo Bustelo escribe en El País (12-12-97, p. 58) «Las crisis asiáticas, ¿el 


\subsection{Del crecimiento a la reducción de la pobreza}

Ya hemos señalado que sin crecimiento no es posible mantener una eficaz lucha contra la pobreza. Pero el crecimiento por sí mismo no es suficiente para avanzar en desarrollo humano, es igualmente importante la distribución de la riqueza: la manera en que se «reparte la tarta» entre ricos y pobres, hombres y mujeres, regiones y grupos étnicos.

Pero hay una consideración que va más allá de la redistribución de la riqueza: no es sólo cómo se reparte la tarta, sino quiénes participan y de qué manera, en cocinarla.

El bienestar social no depende sólo del crecimiento; y el ingreso, depende básicamente de la distribución de los recursos productivos, incluyendo en éstos el capital humano, lo que contempla su educación y salud.

La mejora en el acceso a la educación y la salud fortalece la participación de los pobres en el crecimiento económico, y en el reparto de los beneficios que del mismo se obtienen. En la medida en que se participa en cocinar la tarta se tienen mejores opciones en su reparto.

El crecimiento ha sido un motor esencial en la reducción de la pobreza en el Este de Asia, pero además de un crecimiento alto, esta región se ha diferenciado de otras en que el grado de conversión de crecimiento en reducción de la pobreza ha sido mucho mayor. La «elasticidad de la reducción de la pobreza respecto al

principio del fin?». Primero se señala que coexisten dos crisis diferentes: una de balanza de pagos, causada por el déficit corriente que provocó el anclamiento de las divisas al dólar, y que afecta a Tailandia, Indonesia y Malasia. La segunda crisis afecta a Japón y Corea del Sur y se trata de dificultades financieras sufridas por bancos que han concedido alegremente créditos masivos a proyectos dudosamente rentables. A otros países como China, Hong Kong, y Taiwan la crisis está afectándoles poco. No obstante, si exagerar la gravedad de la crisis es tentador, minimizar sus efectos es arriesgado. Las potencialidades de baja inflación, gran capacidad de ahorro y desarrollo sin precedentes del capital humano ofrecen un panorama esperanzador para la región, pero que está sujeto a dos condiciones fundamentales: la responsabilidad del gobierno de China, que debe evitar bruscas devaluaciones del yuan para competir con sus vecinos, cuyas divisas se han desplomado, y del gobierno japonés, que debe superar el temor a un aumento de su déficit presupuestario y asumir su papel de locomotora de la zona, como hizo EE.UU con Méjico en 1994-1995. De lo contrario las consecuencias de las crisis sí pueden hacerse más graves. 
crecimiento» mide los puntos porcentuales que disminuye la pobreza por cada punto porcentual de crecimiento de la economía. En Malasia, China e Indonesia es de un 3\%. En Nigeria, el país más poblado del África Sub-sahariana es 1,4\%, en Brasil es menos de $1 \%$.

Con estos datos no extrañará que pese a haber crecido entre 1990 y 1995 a una media de $2 \%$ anual, América Latina ha visto como el número de pobres pasa de 197 millones de personas a 209 millones. Según la CEPAL la indigencia ha bajado en este tiempo del 18 al 17\%. Es decir una de cada seis familias no puede satisfacer sus necesidades alimenticias.

Con las actuales perspectivas de débil conversión del crecimiento en desarrollo humano, no parece que sea posible una rápida reducción de la pobreza en este continente. Los datos para Africa Sub-sahariana y el Sur de Asia son aún más desalentadores, ya que la debilidad de la conexión entre crecimiento y reducción de la pobreza son mayores.

\subsection{Distribución del ingreso y reducción de la pobreza}

La distribución de los resultados del crecimiento está fuertemente marcada por la distribución preexistente de los ingresos. La asimetría existente entre los

\section{GRÁFICO 5}

Media de ingreso del $10 \%$ más pobre...

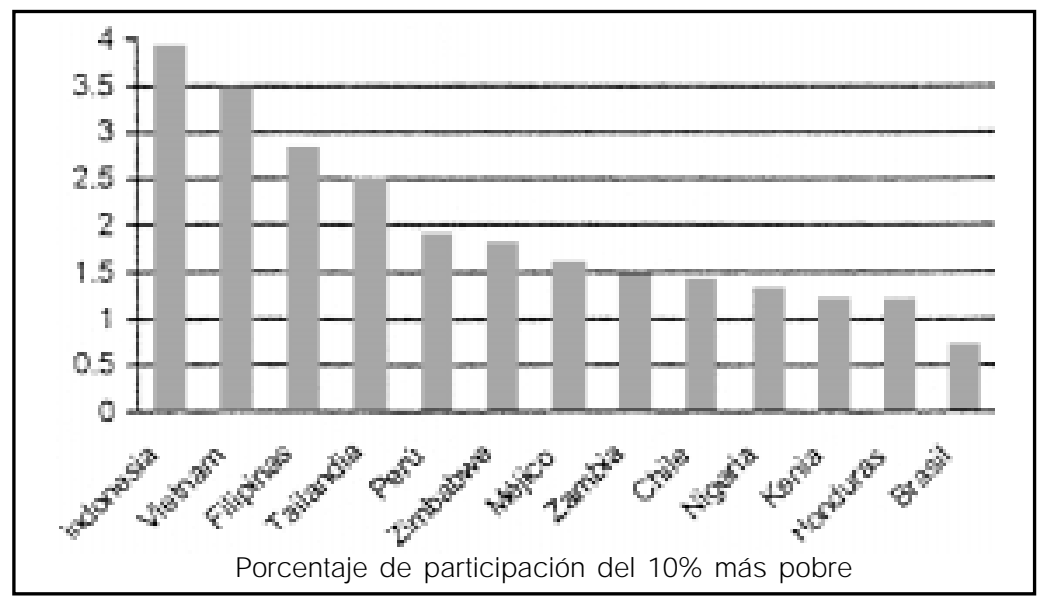


ingresos de los segmentos más enriquecidos y más empobrecidos de una sociedad marcará la elasticidad de la reducción de pobreza respecto al crecimiento, ya que la riqueza se distribuirá sobre la base de los patrones existentes.

Estos patrones de distribución de renta explicarían que, un país como Brasil, que ocupa el quinto lugar en el número de pobres, consiga logros raquíticos en la erradicación de la pobreza, aun en los momentos de crecimiento. Esta consideración sería válida para toda América Latina.

La modificación de los patrones de ingreso influye directamente en la reducción de la pobreza. Así Malasia creció en los años 60 al 6\% anual, con grandes diferencias en la distribución de la renta, manteniéndose por debajo del umbral de la pobreza un $60 \%$ de la población. El goteo del crecimiento no funcionaba para los pobres. Desde 1971 se adoptaron medidas de erradicación de la pobreza que supusieron programas sociales que absorbieron hasta el $60 \%$ de los presupuestos, dirigidos a los pequeños productores y a sectores marginales. El crecimiento económico mejoró, pero sobre todo mejoró la situación de los pobres: su porcentaje pasó del $60 \%$ al $18 \%$ del total de la población. La mejora de la distribución de la renta fue clave: el $20 \%$ más pobre aumentó en un tercio su participación en el ingreso entre 1973 y 1987.

\section{GRÁFICO 5bis}

\section{... Y media de ingreso del $10 \%$ más rico}

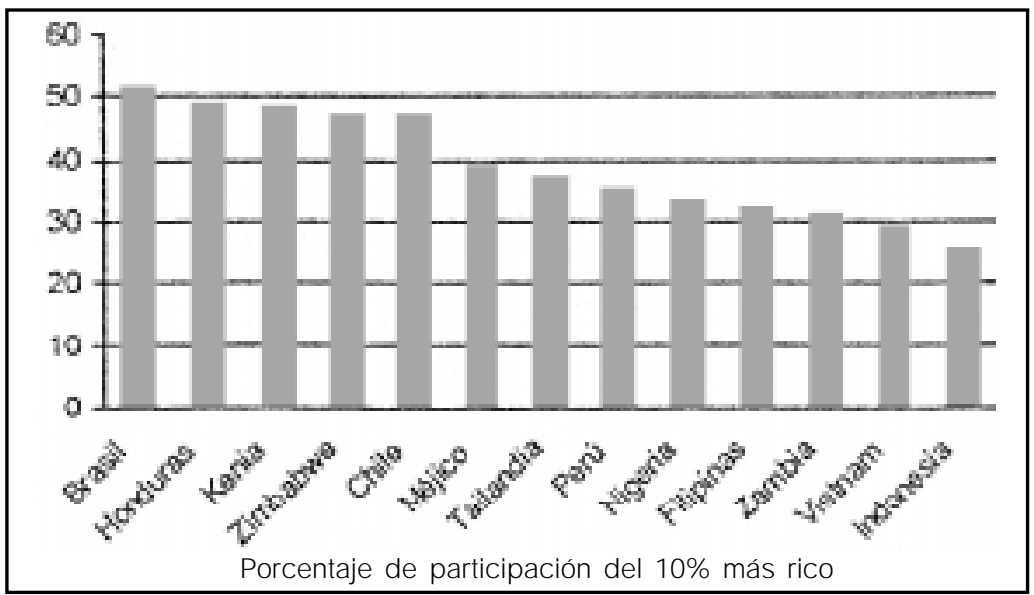

Fuente: Oxfam Internacional. 
Sin embargo en América Latina, desde 1980, con la crisis económica, se acentuaron las diferencias de distribución de rentas: el 20\% más rico pasó de tener un ingreso 10 veces superior al del $40 \%$ más pobre, a tener un ingreso 12 veces superior. En esta década, y según el BID, 100 millones de personas engrosaron las filas de los pobres. Sirva el siguiente cuadro de comparación de Perú e Indonesia como ejemplo (11):

CUADRO $n^{\circ} 7$

\begin{tabular}{|l|c|c|}
\hline & $\begin{array}{c}\text { PIB per cápita } \\
\text { (US \$) }\end{array}$ & $\begin{array}{c}\text { Ingreso menor a 1 US\$ } \\
\text { diario }(\% \text { población })\end{array}$ \\
\hline Indonesia & 880 & $15 \%$ \\
\hline Perú & 2.110 & $49 \%$ \\
\hline
\end{tabular}

Fuente: PNUD

Con la proporción de pobreza existente en Perú, en Indonesia habría otros 30 millones de personas viviendo con menos de 1 dólar al día.

Aunque hay excepciones, la norma general es que exista una correlación entre la distribución equitativa de los ingresos y el crecimiento económico. Podemos obtener la lección siguiente: altos niveles de inequidad son malos para la reducción de la pobreza, pero también lo son para el crecimiento. Por lo tanto, los gobiernos que hagan apuestas serias por el crecimiento tienen que plantearse apostar por la redistribución de los ingresos.

La experiencia de los países de Este de Asia demuestra que el mito por el cual son incompatibles políticas de crecimiento y políticas sociales, y que los logros en una sólo son posibles a costa de los sacrificios en la otra, es insostenible.

El caso de Chile ha sido utilizado para justificar este mito. Chile comienza su recuperación económica en la segunda mitad de los 70. Paralelamente se da uno de los procesos de profundización de la inequidad más bruscos de la historia: se da marcha atrás a la reforma agraria y se aplica un plan de estabilización restrictivo. El 10\% más rico llegó a obtener el 37\%, y entre 1970y 1990 el número de hogares que vivían bajo el umbral de la pobreza se dobló. El crecimiento de

(11) Datos para el período 1989-1994, recogidos en el Informe sobre desarrollo humano 1997, del PNUD. 
la economía tras 1984 es presentado como demostración de que la incompatibilidad entre justicia y crecimiento es real, y que la falta de equidad en la distribución de la riqueza es una condición dolorosa, aunque necesaria, para el crecimiento.

Lo cierto es que la aceleración del proceso de crecimiento no se produjo hasta 1986, y que se ha consolidado desde los 90, cuando políticas que buscan la equidad más decididamente han sido aplicadas. Es decir, el crecimiento lento de la década de los 70 de Chile, así como el de otras zonas en desarrollo se debe en parte a que no son equitativos en la distribución de las oportunidades de desarrollo humano (empleo, acceso a la tierra y al crédito, acceso a la salud y acceso a la educación).

La comparación de dos países superpoblados como son China e India también arroja datos sobre la relación entre crecimiento y equidad. Los progresos en la erradicación de la pobreza en China han sido espectaculares. En la India ha habido progresos en agricultura, industria y en la pobreza de ingreso, pero se mantienen agudos contrastes. Comparando ambos países se encuentran no sólo diferencias en la reducción de la pobreza, sino también en el crecimiento económico, como señala el siguiente cuadro (12).

\section{CUADRO $\mathrm{n}^{\circ} 8$}

\begin{tabular}{|c|c|c|}
\hline Variables & CHINA & INDIA \\
\hline Analfabetismo adultos & & \\
\hline 1970 & $34 \%$ & $66 \%$ \\
\hline 1994 & $19 \%$ & $48 \%$ \\
\hline Tasa mortalidad lactantes & & \\
\hline 1960 & $150 \%$ \% & $165 \%$ \\
\hline 1994 & $43 \%$ \% & $74 \%$ \\
\hline Menores de 5 años desnutridos & & \\
\hline 1975 & $26 \%$ & $71 \%$ \\
\hline $1990-96$ & $16 \%$ & $53 \%$ \\
\hline PIB per cápita (US\$ 1987) & & \\
\hline 1960 & 75 & 435 \\
\hline 1994 & 206 & 407 \\
\hline
\end{tabular}

Fuente: PNUD

(12) Datos recogidos en el Informe sobre desarrollo humano 1997, del PNUD. 
En la India, el período en el que se dieron los principales avances en reducción de la pobreza fue en el período que va de mediados de los 70 hasta las reformas económicas de 1991. En esta etapa el crecimiento fue del 4\% (6\% en los últimos 5 años).

Desde esta reforma, se ha producido una importante industrialización en algunos sectores de tecnologías punta, pero los logros han sido más bien modestos. Por el contrario el crecimiento del PIB chino en los últimos años es alto y sostenido.

De esta manera, aunque el debate sobre crecimiento y equidad es y será amplio, la experiencia de los países del Este de Asia señala que el crecimiento puede ser exitoso apoyándose en la reducción de la pobreza. Y aunque no parece posible establecer conexiones causales irrefutables, esta experiencia sugiere que existe una influencia positiva entre equidad y crecimiento. Según esto, si los gobiernos de América Latina quieren tomarse en serio el crecimiento de sus economías, deben comenzar por tomarse en serio mejorar la equidad de sus países y reducir la pobreza.

\section{El eje del desarrollo humano: las políticas sociales}

A pesar de las limitaciones ya aludidas y sobre las que volveremos, y de las grandes diferencias existentes, el Este de Asia brinda sin embargo algunas lecciones de posible interés para otras áreas del planeta.

La inversión en educación, sobre todo educación primaria, y el acceso de la población a la salud son dos aspectos que potencian el crecimiento económico, al capitalizar los recursos humanos y permitir a los pobres que formen parte del crecimiento económico, contribuyendo a él y beneficiándose del mismo.

Los casos de Corea del Sur e Indonesia ilustran la apuesta por la educación primaria: Corea del Sur pasó de tener a principios de los años 50 apenas el 13\% de su población escolarizada a que 15 años más tarde la mitad de la población hubiera accedido a la educación primaria y el 20\% a la secundaria. En 30 años la escolarización media aumentó en 5 años. En la actualidad los estudiantes coreanos tienen uno de los niveles de formación más altos del mundo. Este avance fue posible gracias a una fuerte ayuda externa de los EE.UU., pero gracias a esta inversión inicial en educación se crearon las condiciones para un crecimiento que ha permitido disminuir la dependencia inicial. La ayuda al 
desarrollo, cuando es adecuada funciona.

En Indonesia, la escolarización primaria pasó de un 30\% a principios de los 60 a más del 60\% en 1973. En los 70 se eliminaron las tasas de la educación primaria, se mejoró la formación del profesorado y se edificaron escuelas. El resultado es que en los 80 más del $90 \%$ de los niños en edad escolar están escolarizados. Como en Corea, la ayuda externa permitió hacer funcionar los primeros planes de desarrollo social. El posterior crecimiento económico y los ingresos del petróleo han permitido asumir los programas sin ayuda externa.

Pero la inversión no debe restringirse sólo a la educación primaria. El caso de Tailandia e Indonesia ilustra las consecuencias de la diferente inversión en la educación secundaria. En la década de los 80 el crecimiento en Tailandia fue mayor que en Indonesia, y sin embargo mientras que en Indonesia el número de personas viviendo por debajo del umbral de la pobreza pasó de 47 millones a 27 millones, en Tailandia incluso aumentó. La explicación puede estar en la diferente orientación de la política de inversiones en educación secundaria. Tailandia la descuidó, y comprobó cómo la evolución de la economía dejó relegados a amplios sectores de la población que sólo contaban con educación primaria. Pero no sólo se debilitaron los efectos del crecimiento económico en la reducción de la pobreza. Una economía cada vez más tecnológicamente avanzada demanda un mercado laboral homogéneamente capacitado. La falta del mismo puede ser una de las razones de la ralentización del crecimiento económico (13).

Respecto a la salud, especialmente en China y Vietnam hay datos muy significativos de cómo el sistema de salud comunal ha alcanzado logros importantes. Sirvan los siguientes datos (14):

(13) Gorostiaga, X., art. cit. Para este autor, exrector de la Universidad Centroamericana de Managua, un énfasis en la educación primaria aisladamente equivale a formar obreros para las maquilas (zonas francas de manufacturas para la exportación). El esfuerzo ha de hacerse en un continuo educativo, en el que la universidad supere la etapa en la que ha sido rehén de la izquierda más dogmática o de las oligarquías locales y sea el motor de la formación de los docentes que protagonizarán la elevación de los niveles educativos.

(14) Datos recogidos en el Informe sobre desarrollo humano 1997, del PNUD 


\section{CUADRO $\mathrm{n}^{\circ} 9$}

\begin{tabular}{|l|c|c|c|c|}
\hline Variables & VETNAM & CHINA & PERÚ & BRASIL \\
\hline Gasto público salud per cápita (US\$ 1990) & 13,28 & 54,68 & 69,25 & 178,13 \\
\hline $\begin{array}{l}\text { Partos asistidos por personal de salud } \\
\text { capacitados (\%) 1990-1996 }\end{array}$ & $95 \%$ & $84 \%$ & $52 \%$ & $81 \%$ \\
\hline $\begin{array}{l}\text { Tasa mortalidad materna (por 100.000 } \\
\text { nacidos vivos) }\end{array}$ & 160 & 95 & 280 & 220 \\
\hline $\begin{array}{l}\text { Tasa mortalidad menores 5 años (por } \\
\text { 1.000 nacidos vivos) }\end{array}$ & 45 & 47 & 55 & 60 \\
\hline $\begin{array}{l}\text { Población sin acceso a servicios de salud } \\
\text { básicos (\%) 1990-1995 }\end{array}$ & $10 \%$ & $12 \%$ & $56 \%$ & - \\
\hline
\end{tabular}

Fuente: PNUD

\section{GRÁFICO 6}

\section{Gasto en salud por regiones (\% PIB)}

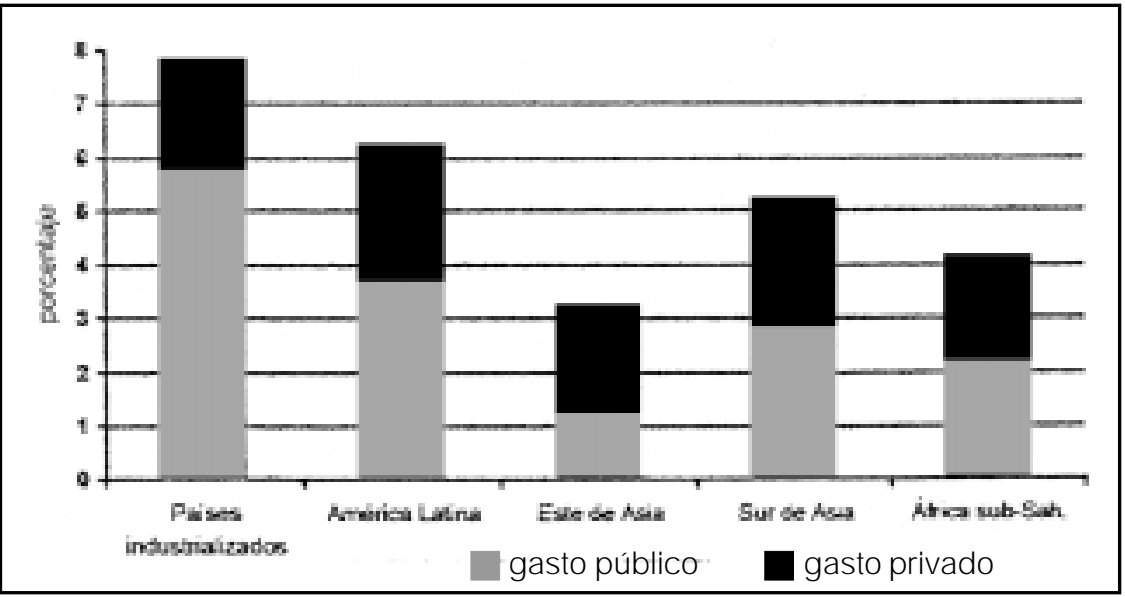

Fuente: Banco Mundial y BID.

Estos datos ponen de manifiesto que la gran diferencia entre América Latina y los países del Este de Asia no está en la cantidad de gasto, sino en la orientación del mismo a los más pobres, obteniendo por cada dólar invertido, índices de 
retorno en bienestar de la población mucho mayores. Los datos de América Latina son la prueba evidente de que más inversión no significa mejores resultados. La realidad es que en los países de América Latina las inversiones en sanidad y educación se traducen en prestaciones de un muy alto nivel (universidades y hospitales localizados en las ciudades) para quienes las pueden pagar, dejando vastas zonas y amplios sectores de la población absolutamente desatendidos, dedicando para la educación primaria porcentajes menores de lo que se dedica en el Este de Asia y renunciando a políticas de atención sanitaria primaria y preventiva que obtienen a muy bajo costo muy altos resultados.

Las políticas sociales de América Latina, con su desacertado enfoque, debilitan las relaciones que existen entre crecimiento y desarrollo humano. Además, las políticas de ajuste impuestas por el Banco Mundial y el FMI están propiciando sensibles recortes de los gastos sociales.

Así, pues, podríamos sacar cinco lecciones de la experiencia del Este de Asia para las políticas sociales de América Latina.

\section{Partidas presupuestarias y composición del gasto}

Hay que destinar un mínimo del 5\% del ingreso nacional a educación y un mínimo del $2 \%$ a salud. Este gasto debe estar bien balanceado entre inversión publica y privada, debiéndose destinar en los países con menos grado de escolarización o mayores índices de deserción un mínimo de entre el 80 y 90\% del gasto de educación a educación primaria y primeros grados de secundaria, y al menos un $70 \%$ del gasto de sanidad en atención primaria y medidas preventivas.

\section{Gasto público en bienes públicos}

Es preciso asegurar la provisión mediante gasto público y de manera gratuita del tratamiento para las enfermedades infecciosas más comunes, la atención de la gestación y parto y la atención infantil. La educación primaria debiera ser completamente gratuita. Sirva de ejemplo de un país como Uganda, uno de los más pobres del mundo, que está avanzando en estas políticas sociales.

3. Reversión de los «derroches» presupuestarios a gastos sociales Los derroches a los que nos referimos son básicamente tres: 
a) Los gastos militares. Baste como ejemplo los 350 millones de dólares que ha gastado el gobierno peruano en la compra de 12 Mig-29 a Bielorrusia, cuando la mitad de su población (fundamentalmente campesino indígena en los Andes) carece de cobertura sanitaria elemental.

b) La corrupción. Que no sólo supone perder recursos (como los millones de dólares evadidos recientemente en Ecuador por el ex presidente Abdalá Bucaram), sino que resta capacidad a los gobiernos de luchar contra la pobreza y sesga las decisiones a favor de operaciones intensivas en uso de capital donde son más plausibles las comisiones en detrimento de las intensivas en mano de obra y que beneficiarían a los pobres.

c) Subsidios a sectores públicos. Para mantener una cantidad reducida de puestos de trabajo, se consumen partidas importantes del presupuesto, en ocasiones mayores que las que se destinan a educación primaria y salud.

4. Sistema fiscal progresivo

En América Latina los pobres soportan en mayor medida la política fiscal que

\section{GRÁFICO 7}

\section{Ingresos por impuesto a la renta (\% PIB, media 1990-1995)}

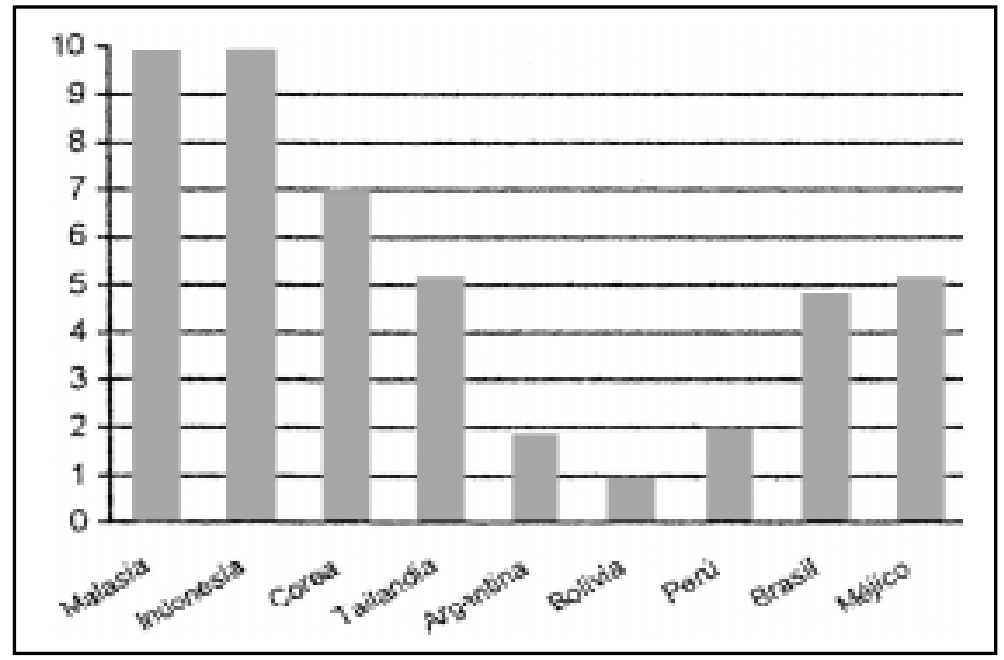

Fuente: Oxfam Internacional 
en otras regiones en desarrollo, y notablemente más que en el Este de Asia, por la presión que ejercen los impuestos indirectos al consumo, la principal fuente de ingresos de la Hacienda Pública. Con niveles mayores de ingresos, los impuestos sobre la renta, que son los que propician la redistribución de la riqueza, generan menores ingresos en América Latina que en los países del Este de Asia, como señala el gráfico $\mathrm{n}^{\circ} 7$.

La creación de impuestos específicos, como los que el gobierno de Corea impone a los beneficios y dividendos y que destina a financiar la educación, podría aplicarse a los beneficios de las grandes explotaciones agrarias, y tendrían la ventaja de aportar efectos positivos en eficiencia y en equidad.

\section{Apoyo de la cooperación internacional}

Jugaría un importantísimo papel en varios aspectos:

a) La deuda externa. Con niveles de absorción de los recursos de más del $50 \%$ (como en Nicaragua u Honduras), la financiación de las políticas sociales resulta muy difícil. La iniciativa HIPC (Países Pobres Altamente Endeudados, en su sigla inglesa) propone dejar los niveles de deuda de los países más pobres a niveles asumibles por ellos en un plazo de seis años.

b) Ayuda internacional. Corea del Sur e Indonesia pudieron financiar sus programas de escolarización gracias a la ayuda externa masiva que recibieron. Esta ayuda, bien dirigida, contribuyó al autodesarrollo y al crecimiento, lo que ha permitido a estos países superar la dependencia ante la cooperación internacional. En la actualidad, el conjunto de la OCDE ha rebajado los montos de su ayuda, situándose en torno al 0’27\% del PIB conjunto. Por referirnos a España, nuestro país se sitúa por debajo de esta media, en un 0’24\% del PIB. Y lo que es más grave es que la Ayuda Oficial al Desarrollo subordina el objetivo de contribuir al desarrollo humano al de favorecer los intereses comerciales de empresas españolas. Los países donantes deben reorientar la AOD, destinando las cantidades que garanticen la escolarización primaria y la atención básica en salud.

La AOD bilateral española dedicada a servicios sociales en 1995 fue en el 4'1\% para enseñanza básica, 5'9\% para salud primaria, 1'8\% para agua y saneamiento y 1'5\% para créditos para los más pobres. En 1996, la cantidad total dedicada a servicios sociales bajó del 13'3\% al 11\% del total de la AOD. La AOD media de los países de la OCDE que informan sobre 
sus aportaciones en salud y educación básicas es del 1'8\% y del 1'2\% respectivamente. Además, en 1995 el total de la ayuda bilateral para educación, sanidad y acceso al agua ascendió al 17\% de lo comprometido (15).

c) Comercio de armas. El $80 \%$ de las armas que se venden provienen de países presentes en el Consejo de seguridad de la ONU. Es necesario restringir por el lado de la oferta el comercio de armas, a través de estrictos códigos de conducta, transparencia en el comercio y restricciones a los países que destinan cantidades excesivas a defensa en detrimento de salud y educación. Sirva el siguiente cuadro de ejemplo (16):

CUADRO $n^{\circ} 10$

\begin{tabular}{|l|c|c|}
\hline & $\begin{array}{c}\text { Gasto en defensa } \\
\text { (MillonesUS\$1995) }\end{array}$ & $\begin{array}{c}\text { Gasto militar } \\
\text { (\% del gasto en educación y salud })\end{array}$ \\
\hline Nicaragua & 34 & 97 \\
\hline Honduras & 47 & 92 \\
\hline El Salvador & 126 & 66 \\
\hline Colombia & 1.195 & 57 \\
\hline Bolivia & 146 & 57 \\
\hline Perú & 817 & 39 \\
\hline Total países en desarrollo & 153.628 & 63 \\
\hline Total países industrializados & 643.515 & 33 \\
\hline
\end{tabular}

Fuente: PNUD

\section{Empleo e industria manufacturera}

Como ya hemos indicado, se suele distinguir entre un modelo de desarrollo basado en la desregulación financiera, la liberalización comercial, la flexibilidad laboral y la mínima intervención del estado, reducido a su mínima expresión y

(15) InTERMón (1997), La Realidad de la Ayuda 1997. Ed. Intermón, España, 141 pp.

(16) Datos recogidos en el Informe sobre desarrollo humano 1997, del PNUD. 
sometido a las reglas del mercado, y otro modelo, en el que el estado juega un papel central en la economía, estableciendo regulaciones al comercio, dirigiendo las inversiones y promoviendo el desarrollo industrial.

Los defensores del primer modelo presentan a los países del Este de Asia como ejemplo del éxito de su receta, y a los países de América Latina y África, como ejemplo del fracaso de la segunda.

La realidad es terca en demostrar que todas las estrategias de desarrollo asiáticas han tenido en común la participación fuerte del estado en orientar las políticas comerciales, financieras y de inversiones hacia el objetivo de un modelo de crecimiento económico basado en el pleno empleo y salarios reales crecientes.

\subsection{El crecimiento de las exportaciones de manufacturas}

El crecimiento económico en los países del Este de Asia está íntimamente relacionado con el crecimiento de las exportaciones de productos manufacturados. La participación de las manufacturas en las exportaciones ha pasado de menos del 6\% a ocupar el $41 \%$ en Indonesia, el $61 \%$ en Malasia y el $77 \%$ en Tailandia.

Los países de América Latina dependen aún en gran medida de materias primas que les proporcionan en torno a un tercio del total de sus ingresos por exportaciones, en tanto que su participación en el comercio de productos manufacturados permanece estancado desde 1970 en torno al 4\%. El deterioro de las relaciones de intercambio de las materias primas ha deteriorado su participación en el comercio mundial (17), y dado que el comercio crece más deprisa que la producción de bienes y servicios, la participación de los países del Este de Asia en los mercados mundiales es mucho más dinámica (18).

(17) Según los datos de la CEPAL, la relación de precios de intercambio FOB/FOB con un índice 100 para 1990 pasó para toda América Latina y Caribe entre 1980 y 1996 de un índice 138 a uno 106, con algunos países que han empeorado notablemente su situación: Bolivia de 134 a 67, Chile de 124 a 96, Ecuador de 166 a 87, Perú de 139 a 94.

(18) GerefFi, G., art. cit. Es posible que los datos no sumen $100 \%$ por errores de aproximación. 


\section{CUADRO $n^{\circ} 11$}

Exportaciones de los NIC del Este de Asia y de América Latina, 1965-1986

\begin{tabular}{|c|c|c|c|c|c|c|c|c|c|c|c|c|}
\hline \multirow[t]{2}{*}{ PAIS } & \multicolumn{2}{|c|}{$\begin{array}{l}\text { Expotaciones } \\
\text { (milmillonesUS\$) }\end{array}$} & \multicolumn{2}{|c|}{$\begin{array}{c}\text { ExportaionesPB } \\
\rho / 9\end{array}$} & \multicolumn{2}{|c|}{$\begin{array}{l}\text { Podutos } \\
\text { Pimaios }\end{array}$} & \multicolumn{2}{|c|}{ RopayTexiles } & \multicolumn{2}{|c|}{$\begin{array}{c}\text { Mequinaizequipos } \\
\text { detrensporte }\end{array}$} & \multicolumn{2}{|c|}{ Oresmanufactures } \\
\hline & 1965 & 1986 & 1965 & 1986 & 1965 & 1986 & 1965 & 1986 & 1965 & 1986 & 1965 & 1986 \\
\hline Taiwan & 0,5 & 39,8 & 18 & 52 & 59 & 9 & 5 & 18 & 4 & 29 & 32 & 44 \\
\hline Hong Kong & 1,1 & 35,4 & 51 & 94 & 13 & 8 & 43 & 35 & 6 & 21 & 38 & 36 \\
\hline Corea del Sur & 0,2 & 34,7 & 7 & 35 & 40 & 9 & 27 & 25 & 3 & 33 & 29 & 33 \\
\hline Singapur & 1,0 & 22,5 & 103 & 130 & 65 & 33 & 6 & 5 & 11 & 38 & 18 & 25 \\
\hline Brasil & 1,6 & 22,4 & 8 & 12 & 92 & 60 & 1 & 3 & 2 & 15 & 6 & 23 \\
\hline Méjico & 1,1 & 16,2 & 5 & 13 & 84 & 70 & 3 & 2 & 1 & 18 & 12 & 10 \\
\hline Argentina & 1,5 & 6,9 & 9 & 10 & 94 & 77 & 0 & 2 & 1 & 6 & 5 & 14 \\
\hline
\end{tabular}

Concretando los destinatarios de las exportaciones y el origen de las importaciones, las relaciones comerciales de los países del Este de Asia entre sí y con Japón, la potencia económica más cercana, resultan intensas.

CUADRO $n^{\circ} 12$

Intercambios comerciales de los países del Este de Asia. Datos de 1995

\begin{tabular}{|c|c|c|c|c|c|c|c|c|c|c|}
\hline & \multirow[t]{2}{*}{$\begin{array}{c}\text { Impotaciones } \\
\text { Milmill.\$ }\end{array}$} & \multirow[t]{2}{*}{$\begin{array}{l}\text { Expotzaiones } \\
\text { Milmill.\$ }\end{array}$} & \multicolumn{4}{|c|}{$\begin{array}{l}\text { Provedores } \\
\text { \%importaciones }\end{array}$} & \multicolumn{4}{|c|}{$\begin{array}{c}\text { Clientes } \\
\text { \%exportaciones }\end{array}$} \\
\hline & & & UE & EE.UU. & Asia $^{1}$ & Japón & UE & EE.UU. & Asia $^{1}$ & Japón \\
\hline CoreadelSur & 135,10 & 125,10 & 14,5 & 23,00 & 46,10 & 24,80 & 15,90 & 22,80 & 45,70 & 14,10 \\
\hline Taiwan & 103,70 & 111,59 & 13,70 & 21,70 & - & 30,20 & 12,00 & 27,10 & - & 10,40 \\
\hline Singapur & 124,51 & 118,27 & 13,10 & - & 66,10 & 22,00 & 13,50 & 18,80 & 59,40 & - \\
\hline Hong Kong ${ }^{2}$ & 192,20 & 173,10 & 10,30 & 7,20 & 37,60 & 15,60 & 15,10 & 23,30 & 32,80 & 5,60 \\
\hline Indonesia $^{3}$ & 40,79 & 44,18 & 20,20 & 11,20 & 57,40 & 27,70 & 17,20 & 17,80 & 59,20 & 30,90 \\
\hline Tailandia & 73,30 & 55,50 & 16,30 & 11,50 & 62,60 & 31,00 & 16,80 & 23,50 & 52,00 & 18,28 \\
\hline China & 129,10 & 148,80 & 16,30 & 12,30 & 58,50 & 23,10 & 12,80 & 17,70 & 60,50 & 17,80 \\
\hline Malasia & 77,53 & 74,05 & 14,80 & - & 59,90 & 26,70 & 14,30 & 21,20 & 58,50 & - \\
\hline Vietnam & 3,92 & 2,99 & 10,40 & - & 58,50 & 11,5 & 7,20 & - & 67,50 & 31,40 \\
\hline Japón & 336,00 & 443,10 & 14,5 & 22,6 & 46,1 & - & 15,9 & 27,5 & 45,7 & - \\
\hline
\end{tabular}

1. Asia, incluido Oriente medio y Japón; 2. China en lugar de Asia; 3. Canadá en el lugar de EE.UU. Fuente: El estado del mundo, 1997. 
Por último, las inversiones extranjeras han tenido un importante papel en el desarrollo industrial. Aunque la crisis de los mercados financieros asiáticos obligue a valorar con mayor cautela el grado alcanzado de inversión especulativa y productiva, podemos afirmar que en América Latina se ha logrado menos canalización de la inversión extranjera a producción intensiva en mano de obra y transferencias tecnológicas que en el Este de Asia.

\subsection{Crecimiento y empleo}

Entre 1986 y 1993 en el Este de Asia se produjo un crecimiento de empleo de más del $3 \%$ anual y de los salarios reales de entre el 3 y el 6\% anual. El resultado ha sido economías con pleno empleo, como señala el siguiente cuadro. La economía de América Latina creció entre 1991 y 1995 a una media del 3\%, pero en esta etapa el paro aumentó. En Argentina, un crecimiento del 3\% se vio acompañado por un crecimiento del desempleo en un $7 \%$.

\section{CUADRO $n^{\circ} 13$}

Datos de población y empleo de las economías del Este de Asia

\begin{tabular}{|l|r|r|r|r|c|}
\hline PAIS & $\begin{array}{c}\text { Población } \\
\text { (millones } \\
\text { hab. 1996) }\end{array}$ & $\begin{array}{c}\text { PIB } \\
\text { (\% variacín anual } \\
\text { 1994-1996) }\end{array}$ & $\begin{array}{c}\text { IPC } \\
\text { (\% variación anual } \\
\text { 1994-1996) }\end{array}$ & $\begin{array}{c}\text { Saldobalanza } \\
\text { C/C } \\
(\% \text { s/PIB 1996) }\end{array}$ & $\begin{array}{c}\text { Tasa de paro } \\
(\%) 1996\end{array}$ \\
\hline Hong Kong & 6,3 & 5,0 & 7,6 & $-1,1$ & 2,8 \\
\hline Singapur & 3,0 & 8,7 & 2,1 & 15,0 & 3,0 \\
\hline China & $1.234,3$ & 11,0 & 16,5 & 0,0 & 3,0 \\
\hline Indonesia & 199,6 & 7,9 & 8,7 & $-3,4$ & 2,2 \\
\hline Corea del Sur & 45,5 & 8,2 & 5,2 & $-4,9$ & 2,0 \\
\hline Malasia & 21,3 & 9,0 & 4,2 & $-5,6$ & 2,6 \\
\hline Filipinas & 72,0 & 4,9 & 8,5 & $-4,2$ & 8,4 \\
\hline Taiwan & 21,6 & 6,1 & 3,6 & 3,7 & 2,6 \\
\hline Tailandia & 60,4 & 8,0 & 5,6 & $-7,9$ & 2,0 \\
\hline
\end{tabular}

Fuente: EL PAIS (05-01-98) de datos tomados del FMI, BAD y OCDE.

La explicación de la pobre elasticidad de la reducción de la pobreza respecto 
al crecimiento de la que hablamos más arriba se explica en gran medida por la pobre elasticidad de creación de empleo respecto al crecimiento. Las razones pueden estar en que la industrialización en América Latina es básicamente intensiva en capital, y la pequeña empresa potencialmente exportadora, creadora de empleo, se encuentra con barreras a la importación que le obliga a proveerse de bienes de producción nacionales más caros, lo que les resta competitividad.

A las pobres cifras de creación de empleo hay que añadir la diferencia en los salarios reales, crecientes en el Este de Asia, mientras que en América Latina, como pone de manifiesto la CEPAL, cada vez más personas que viven por debajo del umbral de la pobreza están empleadas (en Chile la mayoría de los pobres están empleados, con una tasa de crecimiento anual del ingreso real por empleado entre 1980 y 1992 de $-0,3 \%$, de $-2,4 \%$ en Brasil, de $-2,2 \%$ en Argentina y de $-1,6 \%$ en Guatemala, frente a $2,3 \%$ en Malasia, $4,3 \%$ en Indonesia, 5,4\% en Singapur o 8,4\% en Corea del Sur) (19).

Las tendencias comunes que podemos identificar en el Este de Asia para explicar el éxito en el proceso de crecimiento económico con aumento de las exportaciones y creación de empleo serían las siguientes cuatro:

\section{Protección selectiva y sustitución de importaciones}

Como se señala más arriba, todas las economías del Este de Asia han pasado etapas de Industrialización por Sustitución de Importaciones, en las que la protección arancelaria ha sido muy importante. No obstante esta protección ha sido sumamente selectiva y cuidadosa, con países como Corea del Sur y Taiwan que han logrado mantener más liberalizadas las importaciones de bienes necesarios para mejorar la productividad.

\section{Regulación de las inversiones extranjeras}

El Este de Asia es una zona atractiva para los inversores extranjeros desde mediados de los 80, como América Latina lo ha vuelto a ser en los 90. Aunque de diferentes maneras, todos los países del Este de Asia han ejercido algún tipo de control e impuesto exigencias a los inversores extranjeros: Corea del Sur limitando la propiedad extranjera en sectores estratégicos, Malasia obligando a los inversores extranjeros a pagar las importaciones que realizasen con los

(19) Datos recogidos en el Informe sobre desarrollo humano 1997, del PNUD 
ingresos provenientes de las exportaciones (buscando mantener saneada la balanza comercial), en Singapur canalizando la inversión a sectores de alto valor añadido y exigiendo la transferencia de tecnologías y la capacitación del personal local, en Indonesia desde los 80 la inversión extranjera vino acompañada de la importación de tecnología que permitió el despegue de las industrias exportadoras de textiles y calzado.

Pese a los éxitos obtenidos entre 1970 y 1990 en creación de empleo (3\% anual) y en participación de las manufacturas en las exportaciones (del $12 \mathrm{al}$ $80 \%$ ), el caso de Malasia señala el riesgo de no lograr crear vínculos fuertes de la inversión extranjera con la modernización de la industria local. La escasa transferencia de tecnología y capacitación convierte la economía malaya en un enclave de importaciones y exportaciones más vulnerable.

\section{Liberalización selectiva}

De las primeras etapas de fuerte proteccionismo, y comenzando por Corea en los años 60, los países del Este de Asia han ido progresivamente liberalizando sus economías de manera selectiva, buscando siempre que la entrada de capitales extranjeros, bienes y servicios contribuyan a fortalecer el modelo de crecimiento basado en la industrialización intensiva en mano de obra, de progresivo aumento de los valores añadidos y que establezca vínculos que fortalezcan la industria local. En muchas ocasiones la apertura ha venido por las presiones del FMI, del Banco Mundial y de la OMC. En todo caso, puede decirse que aún existe un importante nacionalismo económico, que se ha visto reforzado por la reciente crisis financiera (20).

El modelo de drástica desregulación y liberalización del comercio impulsado por el FMI para América Latina ya ha demostrado su fracaso con la crisis mejicana. Los países del Este de Asia iniciaron los procesos de liberalización después de haber invertido fuertemente en elevar los niveles de capacitación de su fuerza de trabajo. En América Latina la liberalización está costando empleos en lugar de crear oportunidades.

\section{Ahorro}

La mayor capacidad de ahorro de países del Este de Asia, algunos de ellos con

(20) Instituto de Estudios Estratégicos de Londres, art. cit. 
rentas medias menores que los países de América Latina, ha permitido la financiación doméstica de la economía y una menor dependencia de la ayuda exterior (21).

\begin{tabular}{|l|c|c|}
\multicolumn{1}{|c}{ CUADRO ${ }^{\circ}$ 14 } \\
\hline China & $\begin{array}{c}\text { Ahorrointernobruto } \\
\text { (\%delPIB1994) }\end{array}$ & $\begin{array}{c}\text { PIBreal percápita } \\
\text { (US\$1994) }\end{array}$ \\
\hline Corea del Sur & 44 & 2.604 \\
\hline Malasia & 39 & 10.656 \\
\hline Tailandia & 37 & 8.865 \\
\hline Indonesia & 35 & 7.104 \\
\hline Chile & 30 & 3.740 \\
\hline Brasil & 28 & 9.129 \\
\hline Perú & 20 & 5.362 \\
\hline Argentina & 18 & 3.645 \\
\hline Méjico & 18 & 8.937 \\
\hline Colombia & 15 & 7.384 \\
\hline Honduras & 14 & 6.107 \\
\hline Bolivia & 8 & 2.050 \\
\hline El Salvador & 4 & 2.598 \\
\hline Nicaragua & -9 & 2.417 \\
\hline
\end{tabular}

Fuente: PNUD

\subsection{La crisis asiática, lecciones de América Latina para Asia}

En la reciente crisis asiática se han producido en realidad dos crisis de distinta naturaleza: Tailandia, Indonesia y Malasia han sufrido una crisis de balanza de pagos provocada por un enorme déficit de balanza de pagos (8\% en Tailandia

(21) Datos recogidos en el Informe sobre desarrollo humano 1997, del PNUD 
en los tres últimos años) y un tipo de cambio virtualmente fijo frente al dólar. La crisis de Corea y Japón responde a las dificultades financieras de los bancos, que ante la abundancia de capitales se embarcaron en una alegre política de concesión de créditos a empresas sobreextendidas y dudosos proyectos inmobiliarios (22).

La lección que debe sacar Asia es que la receta que el FMI quiere aplicar es la misma que puso en práctica en la crisis mejicana de 1994. Básicamente asegurar a los donantes que recuperarán sus inversiones a costa del recorte de gasto público en educación y sanidad y la reducción del empleo: ante el aparente éxito del plan de rescate de la economía mejicana los datos señalan que quienes han pagado la crisis causada por la ultraliberalización impuesta a las exportaciones mejicanas han sido los pobres: un millón de empleos perdidos, caída de las economías domésticas en un $8 \%$, caída de la inversión en un $40 \%$, caída de los salarios reales en un $30 \%$ y recorte drástico de las inversiones sociales.

La solución y prevención de crisis como la mejicana del 94 y la asiática actual pasa por la acción concertada internacional. La liberalización e informatización de las transacciones financieras han provocado que los gobiernos hayan perdido poder frente a los especuladores (países de Europa, de América Latina y de Asia han sufrido los efectos de las especulaciones de divisas). Para restar esta capacidad de provocar tormentas financieras podría incluirse una tasa uniforme sobre las operaciones de cambio de divisas (23). Un 0’25\% sería suficiente para limar los beneficios marginales que explotan los especuladores, mientras que para las operaciones a largo plazo, la influencia de esta tasa sería inapreciable.

\section{El desarrollo rural a través de la redistribución de las tierras}

La principal lección de los países del Este de Asia en esta área es que, cuando se les da la oportunidad, los pequeños campesinos pueden construir su propio camino para salir de la pobreza y asegurar la alimentación de la población de sus países.

Para que esta oportunidad sea dada las principales políticas a aplicar serían:

(22) Bustelo, P., «Las crisis asiáticas, ¿el principio del fin?», El País (12-12-97, p. 58).

(23) Evidentemente no es una propuesta de sencilla aplicación. Habría que comenzar estableciendo un acuerdo sobre quién fija dicha tasa, ¿el FMI, por ejemplo? 
1. Mejora de la eficiencia y la equidad con la redistribución de las tierras

Las distribuciones de propiedad de tierras altamente desiguales son profundamente ineficientes y generadoras de conflictividad social. El primer paso ineludible en la reforma agraria que aún hoy es imprescindible en América Latina pasa por la redistribución de tierras.

Los países del Este de Asia han dado todos el paso de crear una base de economía de pequeños propietarios, unos evolucionando de un sistema latifundistas (Tailandia, Indonesia), y otros evolucionando de sistemas colectivistas (China y Vietnam). Las reformas han estado en la base de los incrementos de producciones agrarias.

El coeficiente de Gini, que mide la equidad de la distribución de las tierras cultivables desde 0 (equidad perfecta) a 1 (inequidad absoluta), señala que la media en el Este de Asia es de 0,33, mientras que en América Latina es de 0,70 (en Brasil, el 2\% de los propietarios tienen el $80 \%$ de las tierras cultivables).

Se suele oponer una serie de tópicos a la redistribución de la tierra: que los pobres no son eficientes en el uso de los recursos productivos, que las pequeñas granjas no crean empleo ni reducen la pobreza, que las grandes propiedades son las que crean empleo, que las reformas interrumpen los procesos productivos o que crean inestabilidad política. Sin embargo la experiencia del Este de Asia señala que los tópicos son infundados cuando las reformas se hacen de una manera integral.

La reforma agraria no tiene que pasar necesariamente por la privatización de las tierras. El caso chino y vietnamita, donde la titularidad de las tierras no es privada, lo demuestra. De hecho, una privatización en la que prevalezcan los intereses comerciales puede perjudicar a las comunidades que no cuentan con títulos de propiedad, sino que ejercen derechos consuetudinarios de uso de tierras comunes y recursos hídricos considerados de titularidad pública (24).

(24) La reforma basada en privatizaciones ha creado nuevas comunidades de «sin tierras» en Zambia. Por el contrario, en Tanzania se han tenido en cuenta diversos tipos de derecho sobre las tierras. En América Latina las comunidades campesinas disponen con carácter comunal de los derechos de posesión y uso de las tierras altas (páramos) desde hace siglos, pero sin que gocen de títulos de propiedad, como señaló en la sesión que impartió en el programa de doctorado 97-98 de ETEA, Luis Chicaiza, director del proyecto de recuperación de los Páramos en el cantón Cayambe, Ecuador. 


\section{Creación de instituciones de ahorro y crédito para los campesinos}

Los campesinos tienen verdadera capacidad de ahorro, pero carecen de instituciones con las que relacionarse. Por otra parte, tienen prácticamente vedado el acceso a los créditos de la banca comercial. Las ONGD demuestran con sus programas de microcrédito y fondos rotatorios que el grado de cumplimiento de los compromisos de pago por parte de los campesinos pobres supera el $90 \%$. Pero la experiencia de las ONGD, aun siendo valiosa, no ofrece la dimensión que demanda el campesinado de América Latina.

La experiencia del BRI (Bank Rakyat Indonesia) puede servir de ejemplo. De una primera etapa en la que básicamente se prestaba a las élites locales (consideradas de menor riesgo) y en la que no existían programas de movilización del ahorro, se pasó en 1983 a ofrecer un programa de ahorro para los pequeños agricultores basado en la facilidad de operación y el fácil acceso. El BRI ha pasado de tener unos depósitos de US\$200.000 a tener en la actualidad 13 millones de ahorradores y unos depósitos de US\$2.400 millones. La mitad de los ahorradores tienen depósitos por debajo de los US\$12, y la mayoría de los préstamos individuales son a corto plazo (10-12 semanas). La tercera parte de los clientes del BRI viven con ingresos que están por debajo del umbral de la pobreza.

\section{Dotación de infraestructuras de transporte y de comercialización}

Si la comercialización en Lima de un kilo de arroz producido en la región interandina del Alto Huallaga supone mayores costos de transporte que la comercialización de un kilo de arroz tailandés, la reforma agraria que se diera tendría pocas posibilidades de ser viable. La falta de infraestructura de transporte seguirá haciendo que los únicos cultivos rentables sean los de muy alto valor agregado: la hoja de coca para transformación en pasta básica de cocaína.

\section{Protección ante las amenazas del dumping}

Méjico y Filipinas, han abierto sus mercados a la importación de maíz en virtud de los acuerdos de la NAFTA y de la Ronda Uruguay del GATT respectivamente. Las consecuencias han sido que unos dos millones de campesinos mejicanos y un millón doscientos mil filipinos han perdido sus medio de vida, que provenía básicamente del ingreso por el cultivo y comercialización del maíz. Los únicos beneficiados de estos acuerdos han sido los productores de frutas y hortalizas 
para la exportación. Este sector genera el $40 \%$ de los ingresos por exportaciones en Méjico y ocupa solo el 6\% de las tierras. Los campesinos que cultivan maíz, buena parte de ellos pobres, ocupan la mitad de la tierra y generan sólo el $20 \%$ de los ingresos agrarios.

La frágil competitividad de los pequeños campesinos demanda etapas de protección de los mercados nacionales. La amenaza de un sector rural fuertemente subsidiado de EE.UU. y Europa (en torno a US\$180.000 millones anuales gastan los estados de la OCDE en subsidios agrarios y subvenciones a la exportación) no puede permitir la apertura total de los mercados nacionales.

Indonesia ha pasado en 20 años de importar dos millones de toneladas de arroz al auto abastecimiento. El camino ha sido buscar la mejora de la productividad local en lugar la de asegurar la importación masiva de productos baratos (la estrategia nigeriana, que emplea los ingresos del petróleo en importaciones masivas de alimentos). Para ello las inversiones públicas en irrigación e infraestructuras fueron acompañadas por la actuación de una agencia estatal que aseguraba el precio de la producción y restringía la importación de alimentos a precios de dumping. Con estas medidas se disminuye el riesgo de los campesinos, se asegura el funcionamiento del sistema crediticio y se sientan las bases de la seguridad alimentaria y de un sector rural eficiente.

Tailandia abrió sus mercados al arroz estadounidense, con lo que los precios se desplomaron a los niveles más bajos desde 1930. Los resultados fueron la reducción de inversiones en agricultura y el aumento de la pobreza campesina.

\section{Los límites de la enseñanza asiática}

Los indudables logros de los países asiáticos no deben impedirnos valorar las importantes fracturas que se han producido en esta región. Advertir estas aristas oscuras y evitarlas es un reto tan importante como replicar los éxitos señalados.

\subsection{Las desigualdades regionales}

En los 90 el crecimiento del PIB vietnamita ha sido del 6-7\% anual. Un tercio de este crecimiento se ha dado en la capital del país, Ho Chi Minh, mientras que 14 de las 53 provincias del país han experimentado crecimientos negativos del ingreso per cápita. 
Bangkok, capital de Tailandia, tiene una renta media doble de la media nacional y 15 veces superior que las provincias más pobres del noreste.

Las provincias costeras chinas: Jiangsu, Zhejang, Shandong y Guangdong, generan dos tercios de la producción industrial y reciben el $95 \%$ de las inversiones extranjeras. Las provincias montañosas del interior concentran entre la población campesina índices de pobreza mayores a la media nacional.

\subsection{Los desplazamientos poblacionales}

Las explotaciones rurales extensivas y los megaproyectos energéticos, como la presa sobre el río Yang Tse para crear 18.000 MW, están provocando desplazamientos forzados de los grupos más vulnerables.

\subsection{Destrucción del medio ambiente}

La acelerada destrucción del medio ambiente no está teniendo efectos sólo sobre la población local (el Banco Mundial ha calculado en US\$ 500 millones anuales los costos en salud de la polución ambiental y de las aguas de Yakarta). La cumbre de Kioto ha puesto sobre la mesa la dificultad de lograr avances en compatibilizar los intereses de los países pobres en crecer económicamente con una mentalidad de «crecer primero y limpiar el medio ambiente después», los intereses de los gobiernos de los países desarrollados y las empresas transnacionales de energéticos fósiles con la sustentabilidad global del modelo (25).

(25) Azqueta Oyarzun, D., «Calentamiento global, sustentabilidad y desarrollo». El País (09-12-97, p. 34). Señalando esta dificultad propone por un lado que se cree un fondo mundial que retribuya a los países que conserven sus bosques, como manera de reducir el $\mathrm{CO}_{2}$ de la atmósfera -más barata que reduciendo emisiones unilateralmente- y combatir la deforestación, y por otro lado definiendo con criterios técnicos la cantidad de $\mathrm{CO}_{2}$ que puede recibir la atmósfera, y asignando esta cantidad entre los países, imponiendo los recortes mayores a los países causantes del actual problema, los países de la OCDE, pero permitiendo intercambiar y negociar con los «derechos de emisión», que podrían alcanzar altos precios en el mercado. De esta manera la conservación del medio ambiente no coartaría radicalmente las posibilidades de crecimiento de los países pobres. 


\subsection{La negación de los derechos laborales}

La explotación laboral, especialmente de las mujeres y la negación y persecución sistemática de los derechos sindicales es un de los mayores puntos negros de las economías del Este de Asia.

La muerte en 1993 de 188 obreras en una factoría de Kader en Tailandia, y de otras 87 en la factoría Zhili de China, demostraron cómo las empresas jugueteras incumplen gravemente las normas de seguridad en el trabajo para rebajar costes y aumentar los márgenes.

Los bajos salarios, la discriminación de la mujer, el incumplimiento de la normativa de seguridad en el trabajo y la negación de los derechos sindicales es práctica generalizada en países con regímenes políticos autoritarios.

\section{Conclusiones}

La pobreza es una realidad evitable. La experiencia de los países del Este de Asia demuestra que existen efectos positivos mutuos entre la erradicación de la pobreza y el crecimiento económico. Así, tanto desde un punto de vista ético, como desde un punto de vista de eficiencia económica, América Latina debe asumir unas recomendaciones básicas, salidas de las diferentes prácticas exitosas del Este de Asia, que ayuden a construir un camino propio de crecimiento con equidad. Estas prácticas no coinciden con las recetas que desde el FMI se están imponiendo desde hace años en América Latina, y que tras la reciente crisis, amenazan con imponerse también en Asia.

Sea cual sea la validez del modelo asiático, sirvan como conclusiones -que suscribimos plenamente- el sumario de recomendaciones recogidas en la agenda para la reducción de la pobreza de Oxfam Internacional.

Recomendaciones generales:

- Asegurar la inversión publica para crear oportunidades en salud y educación, prestando un servicio de calidad y gratuito a los pobres.

- Promover estrategias de crecimiento industrial que maximicen las oportunidades de empleo.

- Promover el desarrollo rural a través de la redistribución de los recursos y de la dotación a los campesinos del soporte estructural en producción y comercialización. 
Recomendaciones en política social

- Desarrollar un sistema de sanidad público universal y gratuito, basado en la atención primaria y la prevención, que facilite una gama suficiente de servicios.

- Desarrollar un sistema público y gratuito de educación primaria.

- Erradicar las políticas de recuperación de la inversión en salud y educación básica.

Recomendaciones presupuestarias

- No gastar más del 2\% de la renta nacional en presupuestos militares.

- Destinar al menos el 5\% de la renta nacional a educación, asegurando que se destina un $90 \%$ del presupuesto a educación primaria y secundaria básica.

- Cambiar las prioridades del sector sanitario, alejándose de lo curativo y centrándose en la atención primaria y preventiva.

Recomendaciones para la comunidad internacional

- Profundizar la iniciativa HIPC, pasando de un plazo de condonación de 6 años a uno de 3 años y fijando la sostenibilidad de la deuda en 15-20\% de las exportaciones para el servicio de los intereses (en lugar del 20-25\% actual) y del 150-200\% de las exportaciones para el total de la deuda (frente al 200-250\% actual).

- Destinar antes del año 2000 el 5\% de la AOD a educación primaria.

- Dar mayor protección a los presupuestos sociales en los programas de ajuste.

Recomendaciones en política industrial

- Promover la industrialización basada en el uso intensivo de mano de obra y salarios crecientes.

- Regular las inversiones, mediante un código multilateral que reconozca la necesidad de sujetarlas a las prioridades nacionales.

- Crear un pequeño impuesto para las transferencias internacionales de divisa que detenga las inversiones en cartera especulativas.

Recomendaciones sobre desarrollo rural

- Reforma agraria, incluyendo redistribución de las tierras, para crear un sistema de pequeños propietarios.

- Inversiones en infraestructuras viales y de comercialización y promoción de cooperativas de créditos y cajas rurales. 
- Proteger la producción local de alimentos de las importaciones baratas para incentivar la inversión. La Organización Mundial del Comercio debería aceptar esta vía de protección como forma de alcanzar la seguridad alimentaria.

\section{Bibliografía}

Akal Ediciones (1997), El estado del mundo, edición 1997. Ed. Akal. Madrid, España. 1996.

Bustelo, P. (1991), «Pautas comparadas de Industrialización: los NPI de Asia y de América Latina», Boletín Económico de ICE, n 2264, pp. 129-137.

GerefFI, G. (1990), «Los nuevos desafíos de la industrialización: observaciones sobre el sudeste asiático y Latinoamérica», Pensamiento Iberoamericano, nº 16, España, pp. 205-234.

Gorostiaga, X. (1996), «Entre Somalia y Taiwan. ¿Hay otra alternativa?», Envío, no 167, enero-febrero, Nicaragua, pp. 33-43.

InTERMÓn (1997), La Realidad de la Ayuda, Ed. Intermón, Barcelona.

OXfam International (1997), Growth with equity: an agenda for poverty reduction, septiembre, Washington D.C.

Pipitone, U. (1996), Asia y América Latina. Entre el desarrollo y la frustración, CIDE, Madrid.

PNUD (1997), Informe sobre desarrollo humano 1997, Ed. Mundi-Prensa, Madrid.

Provinciales Latinoamericanos de la Compañía de Jesús (1996), Neoliberalismo en América Latina. Aportes para una reflexión común. Documento de trabajo, 14 de noviembre, México. 